Research Article

\title{
Simulation Analysis and Experimental Study on Strength Optimization of a Plug-In Oil Hose Joint
}

\author{
Chang Chen $\mathbb{D}^{1},{ }^{1}$ Jikun Guo, ${ }^{1}$ Shifu Zhang, ${ }^{1,2}$ Qixin Zhang, ${ }^{1}$ Dongmei Zhang, ${ }^{1,2}$ \\ Yongjie Niu, ${ }^{1}$ and Hao Sun ${ }^{1}$ \\ ${ }^{1}$ Army Logistics University of PLA, Chongqing 401311, China \\ ${ }^{2}$ National Engineering Research Center for Disaster \& Emergency Relief Equipment of China, Chongqing 401311, China \\ Correspondence should be addressed to Chang Chen; 408430734@qq.com
}

Received 31 October 2017; Revised 31 January 2018; Accepted 6 February 2018; Published 17 April 2018

Academic Editor: Yee-wen Yen

Copyright (C) 2018 Chang Chen et al. This is an open access article distributed under the Creative Commons Attribution License, which permits unrestricted use, distribution, and reproduction in any medium, provided the original work is properly cited.

A plug-in oil hose joint is used as the research object in this study. Aimed at the problem of pipeline breakage due to insufficient strength of the joint during the process of oil transportation on the sea, a three-dimensional geometric model of the joint is constructed according to the structural characteristics of the plug-in joint. The mechanical properties of the plug-in hose joint were studied by numerical simulations and field experiments. The strength of the joint was optimized by applying materials with different properties and adjusting the circular angle of the joint. The tensile strength test results of the plug-in oil hose joint are consistent with the theoretical analysis, which shows that the method proposed in this paper can effectively improve the tensile strength of the oil hose joint. It is of great significance to expand the scope of the plug-in connector and ensure the safe and stable use of the hose system.

\section{Introduction}

A plug-in connector has the advantage of quick connection and is widely used in a variety of industrial and engineering activities, especially in the offshore soft oil pipeline system. Since characteristics of the soft pipeline include small bending rigidity and high tensile strength, the shape of the soft pipeline can be easily changed to transmit the external load to the hose connector position, resulting in the hose joint becoming the weak part of the entire hose system. This is particularly evident in the use of marine hose systems. If the joint is damaged, oil leakage can occur, along with possible fire and other security threats. Therefore, the study of joint strength has attracted much attention.

During the past decade, the study of joint strength has developed in a variety of directions. Some scholars have studied the fatigue strength of welded joints. Lazzarin et al. tested more than one hundred aluminum symmetric double butt joints to clarify the influence of geometrical, technological, and environmental factors on the fatigue behavior and failure modes of bolted joints [1]. Atzori et al. investigated the possibility of unifying different criteria regarding the fatigue strength of welded joints [2]. Lazzarin and Livieri summarized the fatigue strength of aluminum welded joints with different geometries and thicknesses in a single scatter band by using a notch stress intensity factor- (N-SIF-) based approach [3]. In 2004, Lazzarin et al. found that the critical radius $\mathrm{R}-\mathrm{C}$ was approximately $0.40 \mathrm{~mm}$ for welded joints made of Fe E 460 steel and approximately $0.10 \mathrm{~mm}$ for joints made of AlSilMgMn alloy under high-cycle fatigue conditions [4]. Meneghetti and Lazzarin presented an expression linking the peak stress and local strain energy value, which can be used in plane problems when mode II stress fields are nonsingular (at the weld toe) or of low intensity (at the weld root) [5]. In welded lap joints and cover plates, both mode I and mode II stresses are singular at the weld root, where fatigue cracks are likely to initiate. Meneghetti extended the peak stress method (PSM) to mode II loading conditions and derived an equivalent peak stress, which is used to assess either weld toe or weld root fatigue failures [6]. Al Zamzami and Susmel investigated the accuracy and reliability of hotspot stresses, nominal stresses, effective notch stresses, notch stress 
intensity factors (N-SIFs), and material length scale parameters in estimating the fatigue lifetime of aluminum welded joints [7]. In 2017, Meneghetti et al. defined a so-called equivalent peak stress by adopting the average strain energy density (SED) as a fatigue strength criterion and adopted it to assess either weld toe or weld root fatigue failures in conjunction with a properly defined design curve [8]. Song et al. presented fatigue failure crack initial points and the fatigue failure mode transition relationship between the weld toe and root of load-carrying cruciform welded joints on the basis of LEFM and Williams' notch stress intensity theory. In addition, they proved that the SED approach can be used to assess fatigue failure behaviors for load-carrying cruciform welded joints, since it can effectively reflect failure characteristics [9].

At the same time, other researchers focused on the shear strength of solder joints during aging. Tomlinson and Fullylove tested the single overlap joints of copper and brass soldered with tin and tin-based solders containing $1 \% \mathrm{Cu}$, $3.5 \% \mathrm{Ag}, 5 \% \mathrm{Sb}, 57 \% \mathrm{Bi}, 2 \% \mathrm{Ag}$, and $36 \% \mathrm{~Pb}$ and found that brass joints were generally slightly stronger than copper joints and tended to show more scatter [10]. Aging at 70, 120, 155, and 170 degrees, Chan et al. studied the growth kinetics of the interfacial $\mathrm{Cu}-\mathrm{Sn}$ intermetallic (IMC) layer and its effect on the shear strength of practical LCCC surface mount solder joints for isothermal processes [11]. Poon et al. studied two lead-free solder alloys, namely, 50 tin-50 bismuth (Sn-Bi) and 96.5 tin-3.5 silver ( $\mathrm{Sn}-\mathrm{Ag}$ ), for their use in surface mount solder joints. They found that Sn-Ag solder was better than $\mathrm{Sn}$-Bi solder in terms of residual thermal shock shear strength. In addition, $\mathrm{Sn}$-Bi solder showed good properties when treated with -25-to-85-degree thermal shock [12]. Ahat et al. investigated the microstructure and shear strength changes of $\mathrm{SnAgCu} / \mathrm{Cu}$ and $\mathrm{SnAgCu} / \mathrm{Ni}-\mathrm{P} / \mathrm{Cu}$ surface mount solder joints during thermal aging at 150 degrees and thermal cycling between -40 and 150 degrees [13]. Deng et al. focused on the lap shear behavior of $\mathrm{Sn}-3.5 \mathrm{Ag} / \mathrm{Cu}$ joints as a function of solder yield strength and intermetallic thickness. Their experimental results showed that the shear strength of the solder joints is primarily controlled by the mechanical properties of the solder and not by the intermetallic thickness [14]. Lee and Lee investigated composite lead-free solders fabricated by adding between 0.5 and $3 \mathrm{wt} . \%$ of $\mathrm{Ni}$ particles in situ to $\mathrm{Sn}$ 3.5 wt.\% Ag lead-free solder and found that the single lap shear strength of the joints increases with increasing $\mathrm{Ni}$ addition in the as-reflowed condition but decreases with increasing storage time in the aged specimens [15]. To investigate the formation and growth of the intermetallic compound (IMC) layer at the solder/metallization interface, Nai et al. performed an isothermal aging study on solder joints. In their study, varying weight percentages of carbon nanotubes (CNTs) were incorporated into a $\mathrm{Sn}-\mathrm{Ag}$-Cu solder matrix to form composite solders. The results showed that the presence of CNTs was effective in slowing the growth of the IMC layer [16]. Wei et al. investigated the growth rule of the interfacial intermetallic compound (IMC) and the degradation of shear strength of $\mathrm{Sn}-0.8 \mathrm{Ag}-0.5 \mathrm{Cu}-2.0 \mathrm{Bi}-0.05 \mathrm{Ni}$ $(\mathrm{SACBN}) / \mathrm{Cu}$ solder joints in comparison with $\mathrm{Sn}-3.0 \mathrm{Ag}-$ $0.5 \mathrm{Cu}(\mathrm{SAC} 305) / \mathrm{Cu}$ solder joints, aging at 373, 403, and
$438 \mathrm{~K}$ [17]. Dele-Afolabi et al. performed an analysis of the role played by the addition of carbon nanotubes (CNTs) to the solder matrix of conventional Sn-5Sb lead-free solder, and the shear strength assessment revealed that the composite solder joints presented a superior shear strength property, especially the Sn-5Sb-0.01CNT solder joint sample [18]. Choudhury and Ladani focused on investigating the effect of different volume fractions of IMCs on the shear behavior of microscale solder joints with a $50 \mu \mathrm{m}$ standoff height. Their research shows that the ultimate shear strength and strain to failure are largely dependent on the volume fraction of IMCs. In addition, the far-field or nominal shear strain is completely different than the local shear strain behavior at the solder joint region [19].

There are also experts devoted to the prediction and optimization of lap joint strength. Hattori applied a new adhesive strength evaluation method, using two stresssingularity parameters to single-lap joints, which are generally used as adhesive strength test specimens [20]. Contrary to the two coupled nonlinear governing equations for an adhesive adherend sandwich of the single-lap type, Tong proved that the product of the adhesive strain energy density and the adhesive thickness is equal to the energy release rate J of mode I, mode II, and mixed fractures [21]. Liu and Sawa analyzed the single-lap band adhesive joints of similar adherends subjected to external bending moments as a four-body contact problem using a two-dimensional theory of elasticity (plain strain state). Moreover, they proposed a method for estimating joint strength using the interface stress and strain obtained by the analysis [22]. Different from the traditional methods of either increasing the lap joint area or altering the joint geometry, Sancaktar and Kumar introduced a novel approach for increasing lap joint strength by the selective use of rubber toughening in epoxy. Furthermore, the nonlinear FEA was shown to represent the experimental results more closely than the linear approach [23]. Liu and Sawa conducted stress analysis and strength evaluation of single-lap adhesive joints combined with rivets (i.e., singlelap riveted adhesive joints) under external bending moments by three-dimensional finite element analysis (FEA) [24]. Sancaktar and Nirantar studied the effect of tapering the ends of the adherend on the joint strength and joint deformation behavior of single-lap joint geometry [25]. Campilho et al. predicted the strength of single-lap and double-lap joints by a standard and extended finite element modeling method [26]. Pinto et al. conducted a test with two adhesives (brittle and ductile) varying the adherend thickness and the number, layout, and diameter of the holes to analyze the effect of hole drilling at the overlap on the strength of single-lap joints [27]. Reis et al. discovered that the shear strength of single-lap adhesive joints was influenced by the adherend stiffness, and the highest shear strengths were obtained using high stiffness adherend materials. The overlap length influenced the shear strength in different ways depending on the adherend materials [28]. $\mathrm{Hu}$ et al. investigated the static mechanical performance of adhesively bonded joints after different temperature exposures through a joint quasi-static shear strength test [29]. Since the overall strength of adhesively bonded joints is dependent on the properties of the adhesives, $\mathrm{Xu}$ and Wei performed the assessments of adhesive 
properties systematically through defining both strength mixity and energy rate mixity and using them to characterize the overall strength of metallic single-lap joints [30]. Assuming only a longitudinal normal stress linear distribution in the joint thickness direction, Zhao et al. presented a twodimensional (2D) analytical method capable of providing an explicit closed-form solution to predict the elastic stresses in balanced single-lap adhesive bonded joints [31]. Parida and Pradhan studied the mixed mode fracture behavior of embedded delaminations in lap shear joints (LSJs) made with curved laminated FRP composite panels under uniform applied extension [32]. Valeva and Ivanova considered the application of the shear lag method to investigate the failure mechanism (interface debonding) of joints (with a continuous overlap zone and with a gap in the overlap zone) of a smart structure consisting of two layers (PZT-4 and carbon/glass fiber-reinforced composite) under static load [33]. Adin analyzed the effect of adherend dimensions and scarf angle on the mechanical behavior of different adhesively bonded joints [34].

It should be mentioned that much of the work so far has focused on the prediction and strength optimization of welded joints, lap joints, and solder joints. Little is known about plug-in oil hose joints. We demonstrate through an extensive literature review that the existing models are not capable of handling the specifics of the problem in this study.

This paper aims to determine a method for improving plug-in oil hose joint strength by theoretical analysis and experimental verification. Following the introduction, the remainder of this paper is organized as follows. Section 2 analyzes the operation loads when the pipeline system is applied in a marine situation. Section 3 establishes the structure of the plug-in-type oil transportation hose joint. Section 4 conducts simulation analysis on the strength optimization of plug-in oil hose joints. Section 5 includes experimental studies of the strength optimization of plug-in oil hose joints. Section 6 concludes the paper.

\section{Operation Load Analysis}

When the hose system is used on land, it is less affected by the outside world in general situations. However, for the marine pipeline, the situation is completely different. Considering the environmental factors, the marine hose system is influenced by ocean waves, ocean current, wind load, and so on. In the actual process, since the direction of ocean waves, ocean currents, and wind load action can change at any time, the shape of the soft hose changes frequently, leading to a complex force situation on the pipeline. Considering that the bending moment of the hose joint is small and is mainly subjected to the axial stretching effect, this paper mainly analyzes the mechanical properties and strength optimization of the plug-in hose joint under axial load.

\section{Structure of the Plug-In Oil Transportation Hose Joint}

To facilitate the connection and disassembly of the joint, several auxiliary structures are designed externally. However,

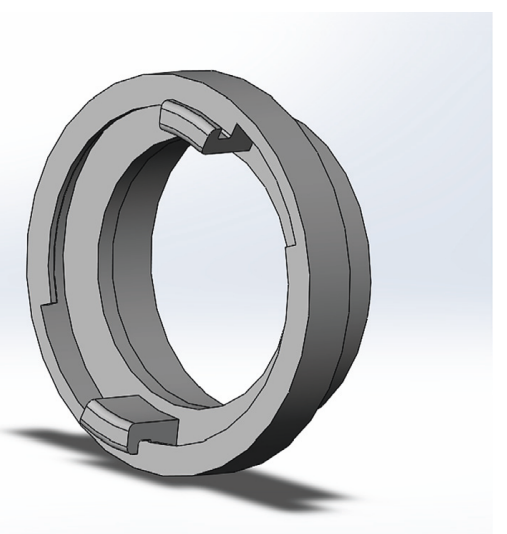

Figure 1: Three-dimensional view of the joint.

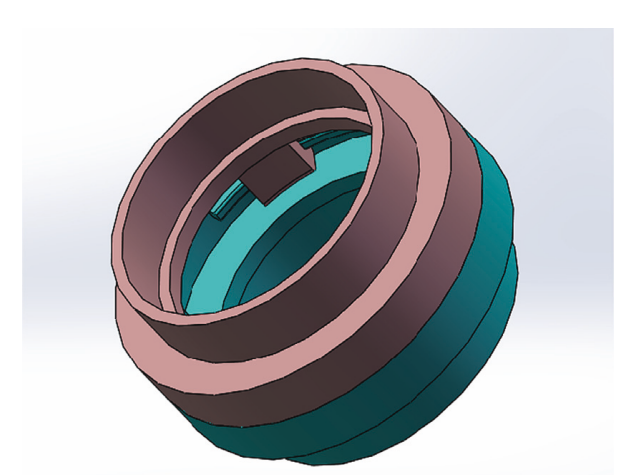

Figure 2: Three-dimensional view of the assembly.

these structures increase the difficulty of modeling the mechanical analysis of the joint and also make few contributions to improving the tensile strength of the joint. Therefore, according to the forces acting on the joint, a threedimensional geometric joint model is established by ignoring the local difference and simplifying the complicated and less influential structure. A three-dimensional view of the joint is shown in Figure 1. The three-dimensional view of the assembly is presented in Figure 2. To better understand the structure of a plug-in oil hose connector, different part views of the joint are presented, which are shown in Figure 3.

\section{Simulation Analysis on Strength Optimization of the Plug-In Oil Hose Joint}

4.1. Model Assumptions. During actual usage on the sea, due to the ocean waves and currents changing at any time, the soft pipeline system is subjected to forces from different directions. Under the action of various loads, the hose is stretched, bent, rotated, and so on. However, because the bending stiffness of the hose is small, the loads are finally transmitted to the hose joint part, resulting in the tensile behavior of the joint in the axial direction. Therefore, this paper assumes that the insert-type connector is only affected by the axial load, and the joint does not bear the torque. Meanwhile, other joint behaviors, such as rotations, are not 


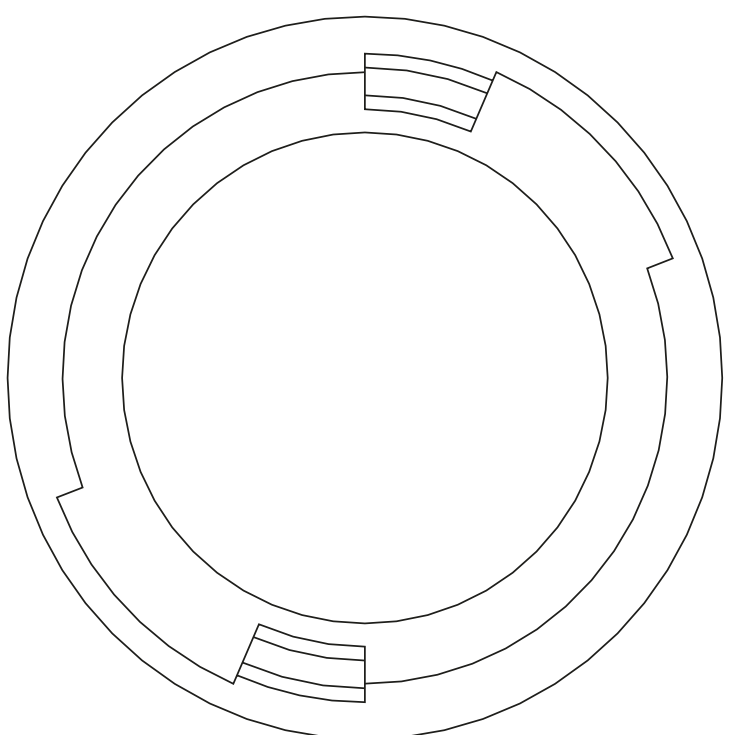

(a)

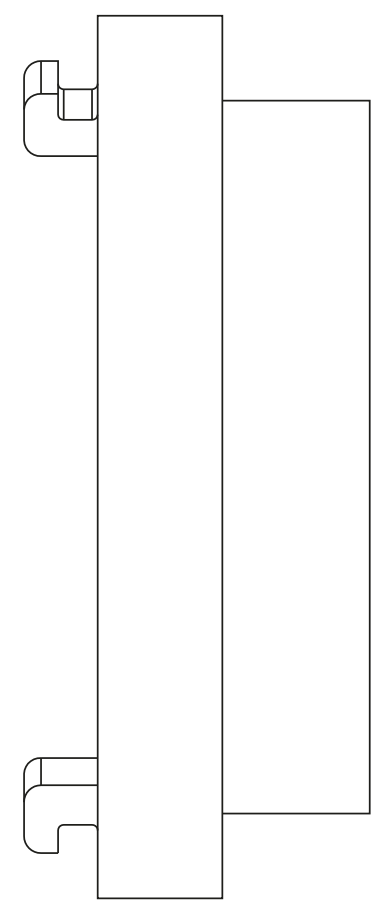

(c)

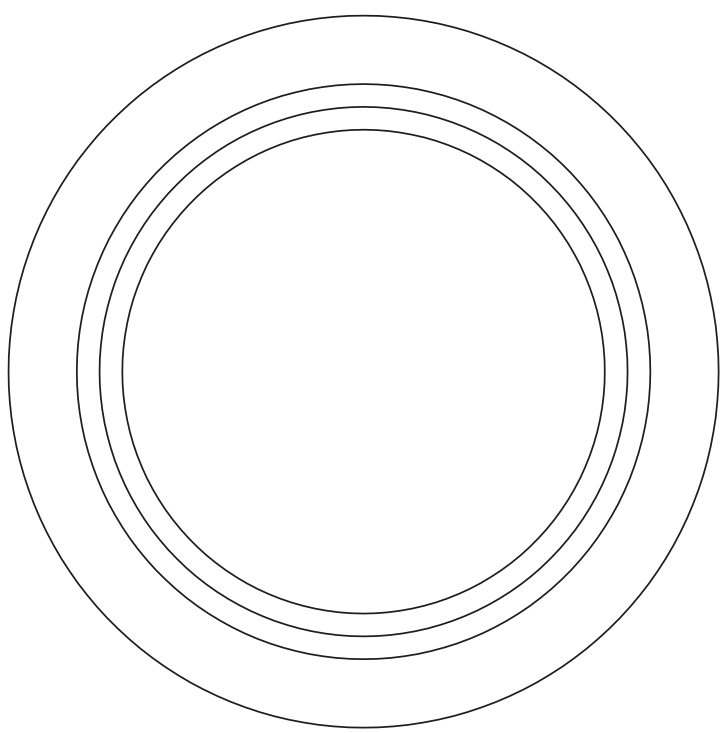

(b)

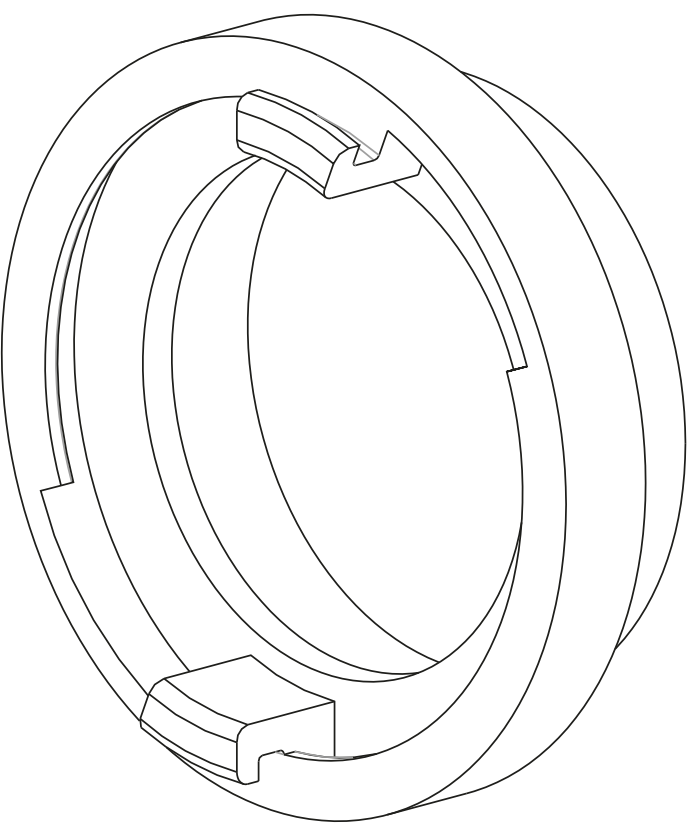

(d)

Figure 3: Different views of the joint. (a) Front view. (b) Back view. (c) Side view. (d) Axial view.

in the scope of the study. In addition, the joint material is uniform, and the joint has no initial defects due to other causes.

4.2. Model Establishment. Based on the basic model of the plug-in connector, a three-dimensional geometric model is established using SolidWorks. To determine the connection position of the connector assembly and its effective width, the angle $\alpha$ between the centers of the symmetrical wedgeshaped part of the joint and the center angle $\beta$ corresponding to the wedge-shaped part are defined, as shown in Figure 4.
First, the plug-in unit is constructed, and the symmetrical units are assembled into connectors. A sectional view of the assembly hose joint is presented in Figure 5. The threedimensional geometric model of the joint is introduced into the HyperMesh software for grid generation, and the grid of the local contact area is encrypted. During this procedure, a total of 20450 hexahedrons were divided, and the unit format was set as a reduced integral hexahedral element, which is shown in Figures 6 and 7. Finally, a geometric model with better mesh quality is imported into ABAQUS for simulation analysis. According to Table 1, the material properties are established, and the section with this material 


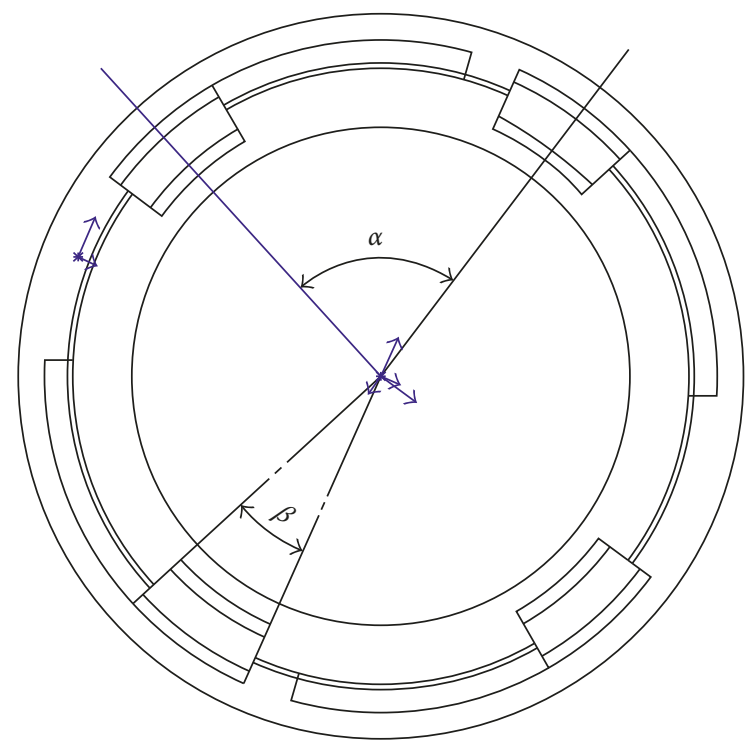

FIgURE 4: Diagrammatic sketch of angles $\alpha$ and $\beta$.

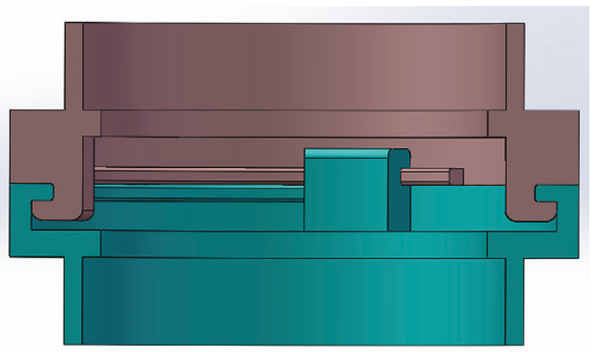

FIGURE 5: Sectional view of the assembly hose joint.

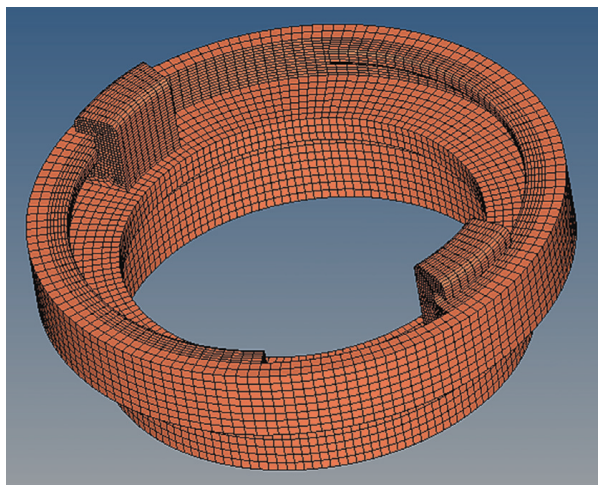

Figure 6: Sketch map of mesh generation.

is built. The static general analysis step is set, and the geometric nonlinearity function is opened. The initial incremental step is 0.1 , the minimum analysis step is $1 E-009$, and the maximum incremental step is 10000 . Furthermore, the contact surface of the assembly hose joint is determined, and the aluminum alloy friction coefficient is defined as 0.3. The left side of the joint is set as the fixed surface, and the displacement along the $x$-axis, $y$-axis, and $z$-axis is fixed. Meanwhile, the right side of the joint is set as the movable

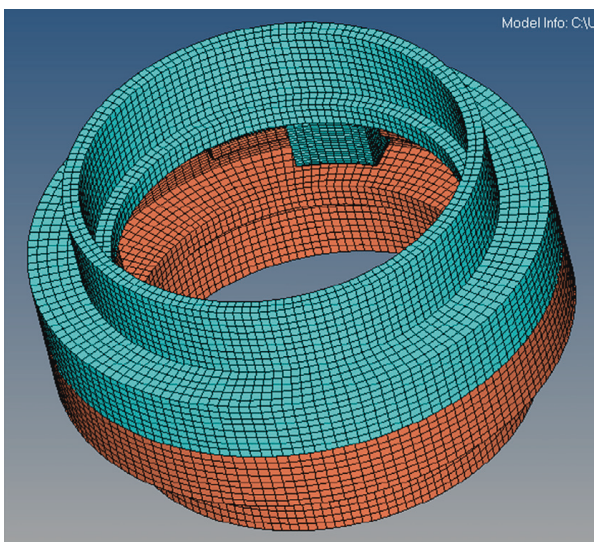

Figure 7: Assembly meshing diagram.

TABLE 1: Mechanical properties of joint materials.

\begin{tabular}{lcccc}
\hline Materials & Parameters & Values & Parameters & Values \\
\hline & $\begin{array}{c}\text { Elastic } \\
\text { modulus } E \\
\text { Aluminum }\end{array}$ & $0.71 \times 10^{5}$ & $\begin{array}{c}\text { Poisson's } \\
\text { ratio } \mu\end{array}$ & 0.31 \\
alloy LY12M & MPa) & & Yield & \\
& Density & $2.8 \times 10^{3}$ & $\begin{array}{c}\text { strength } \\
\left(\mathrm{kg} / \mathrm{m}^{3}\right)\end{array}$ & 300 \\
& & & $\sigma_{0.2}$ & \\
\hline
\end{tabular}

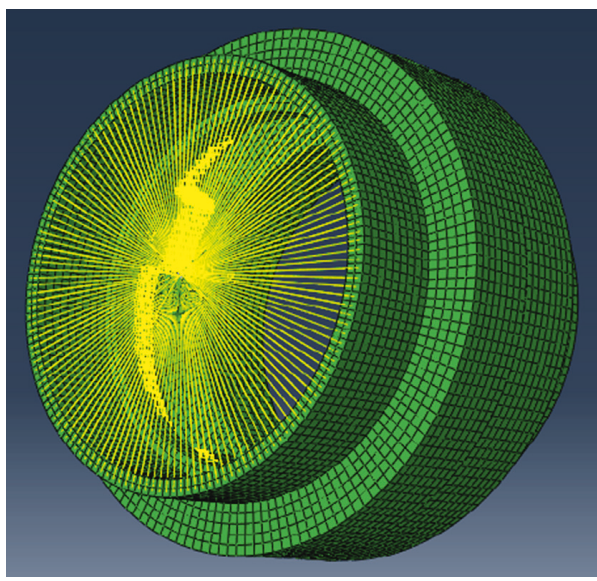

Figure 8: Applied load to the joint.

surface, and a reference point is set at the center of the movable surface, which establishes the coupling constraint with the right side of the joint. In addition, the displacement of the reference point along the $x$-axis and the $y$-axis is fixed, and the movement along the $z$-axis is reserved. The setting process is shown in Figures 8 and 9. Finally, the finite element model is set up and submitted to the standard solver in ABAQUS for analysis and calculation.

\subsection{Numerical Result Analysis}

4.3.1. Strain Analysis of the Plug-In Joint. Figure 10 presents the deformation maps of each part of the joint. The 


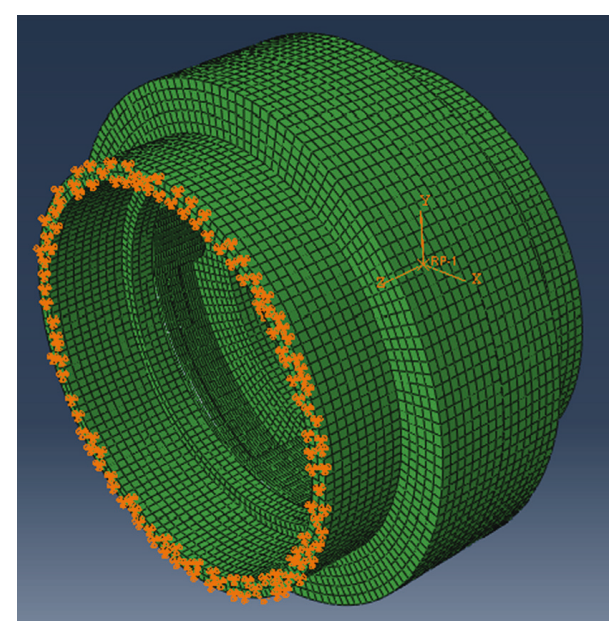

Figure 9: Boundary condition definition of the joint.

preliminary analysis shows that the strain distribution of the fixed and movable ends of the joint assembly is similar. In Figure 10(a), the strain mainly occurs inside the wedgeshaped part of the joint and the connecting part with the joint slot. The strain is limited at other locations.

In Figure 10(b), the strain only occurs at the connecting position with the wedge-shaped part of the joint, and the strain on the outside of the slot portion is greater than the strain on the inside. Along with the direction of slot thickness, the maximum strain occurs at the upper surface of the joint slot, and as the thickness increases, the strain gradually decreases. The strain of the wedge part is mainly concentrated on the inner side and central position of the back side, which is primarily because the wedge part of the joint acts as the main fixing and force-bearing part. In the process of pulling the joint, the inner side of the wedge part is extended to the outside, thereby driving the wedge back into position to shrink inward, resulting in the strain concentration. Figures 10 (c) and $10(\mathrm{~d})$ present the sectional deformation diagram of the wedge-shaped part of the joint and joint slot, respectively.

(1) Strain Analysis of the Plug-In Joint Slot. To accurately analyze the stress and strain distribution of the joint slot, a series of detection points are set along the edges in the XOY plane at different heights of the slot. The relative position of the different monitoring paths is represented by introducing the normalized parameter $A / L$, and $A / L=0$ indicates that the monitoring path is at the bottom edge position of the slot. $A / L=0.2$ indicates that the ratio of the height of the path to the height of the entire slot is 0.2 when considering the bottom edge of the slot as the datum plane. $A / L=1$ indicates that the monitoring path is at the top edge position of the slot. By drawing the strain data of the monitoring points in six different paths, the strain distribution curve of different parts can be achieved as follows.

From Figure 11, the change law of the logarithmic strain components and the equivalent plastic strain are almost equal, and the maximum value of the equivalent plastic strain is greater than that of logarithmic strain components. The strain occurs mainly on the outside of the joint-connecting surface. The maximum strain of the monitoring points in different paths decreases as the path relative position parameter $A / L$ increases, indicating that the strain distribution of the slot is mainly concentrated at the bottom of the connecting part from the perspective of longitudinal direction.

(2) Strain Analysis of the Wedge-Shaped Part of the Joint. Similar to the previous section, a series of monitoring points were set in the YOZ plane with different $X$ values on the surface of the wedge-shaped part of the joint to analyze the stress and strain distribution regulation. Beginning from the bottom of the wedge-shaped part, a monitoring point was selected at every $1 \mathrm{~mm}$ to build the monitoring path. The relative position of the monitoring point is defined by the ratio of the distance of each monitoring point to the starting point at the bottom position and the length of the entire path. The logarithmic strain component and the equivalent plastic strain distribution curves of the different paths of the wedge are extracted, as shown in Figure 12.

In Figure 12, it can be seen that the overall variation of the strain at the wedge-shaped part is in the form of waves, and there are two extreme points in the entire path. For $A / L=0.2$, when the position of the monitoring point begins at the bottom of the wedge to the middle position, that is, the normalized distance of the monitoring point is $0.3 \sim 0.4$, the logarithmic strain value increases rapidly and reaches a maximum value of 0.08 at the normalized distance of 0.4 , indicating that the strain on the entire wedge is centered at the top position of the back of the wedge. The main reason for this phenomenon is that the wedge-shaped part tends to bend toward the inside under the effect of the drawing load, so the maximum change occurs at that position.

4.3.2. Stress Analysis of the Plug-In Joint. The stress distribution of the joint is shown in Figure 13. In Figure 13(a), the stress at the fixed end of the assembly is mainly concentrated in the middle of the wedge part and the connected slot area, and the stress distribution at this part is symmetrical. In Figure 13(b), the connecting area in the joint slot has a significant stress concentration because it is regarded as the main force in the drawing process. The stress in the thickness direction of the edge is also large, mainly due to the transmission of the force within the joint during this process.

Figure 13(c) shows the sectional stress distribution diagram of the wedge-shaped joint section. From the figure, the stress of the wedge-shaped part is mainly concentrated at its top bayonet position, and the stress concentration situation from the upper part to the bottom part gradually decreases. Furthermore, the high stress region in the middle position is narrow. In the middle of the wedge, because of the large thickness, the stress concentration mainly occurs on the inner side, and the degree of stress concentration is smaller on the outside. Figure 13(d) represents the sectional stress distribution diagram of the joint slot. The stress at the joint slot is concentrated in the bending part, and the high stress area in the middle is wider. Therefore, this part is the dangerous area of the joint in the drawing process. 


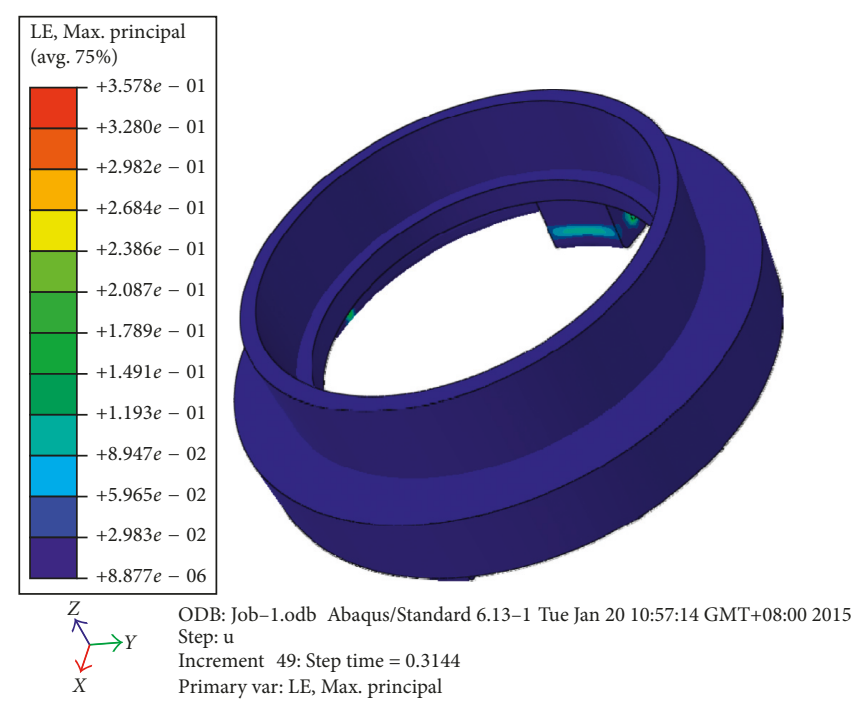

(a)

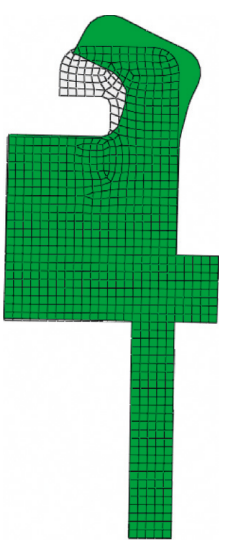

(c)

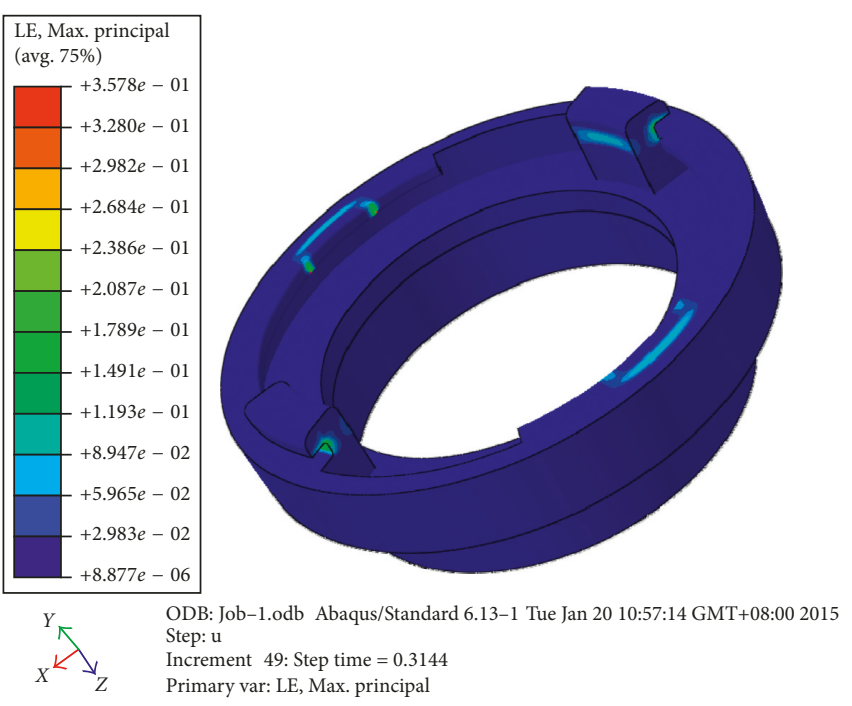

(b)

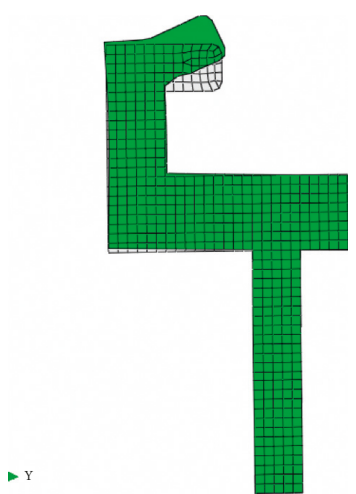

(d)

FIGURE 10: Deformation maps of each part of the joint. (a) Deformation map of the fixed end. (b) Deformation map of the movable end. (c) Sectional deformation diagram of the wedge-shaped part of the joint. (d) Sectional deformation diagram of the joint slot.

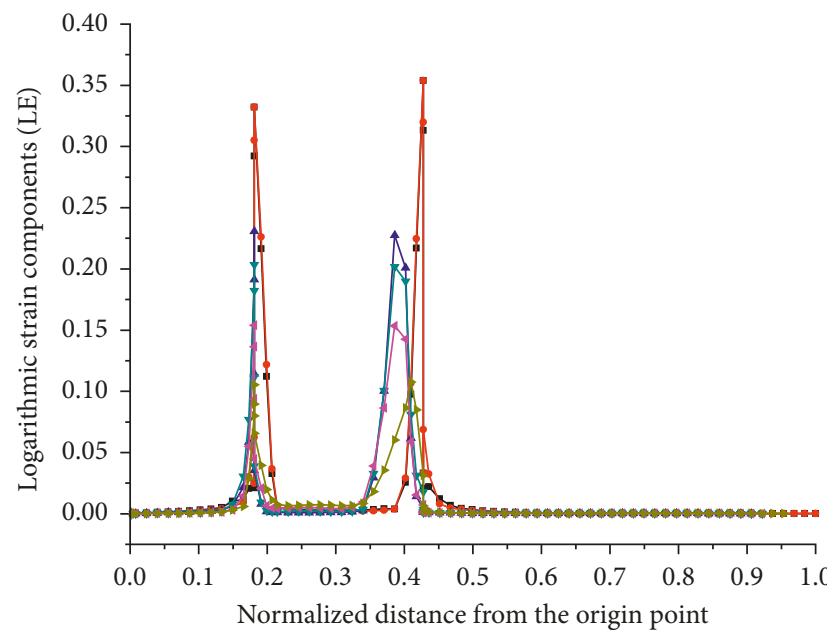

$\longrightarrow A / L=0.0$
$\because A / L=0.2$
$\longrightarrow A / L=0.4$

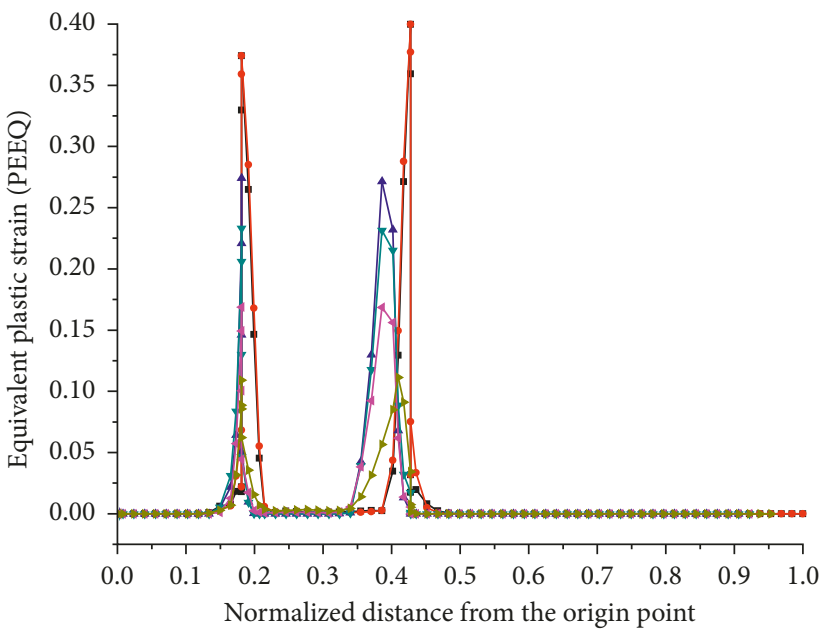

$\begin{aligned} \longrightarrow A / L & =0.0 \\ \longrightarrow A / L & =0.2 \\ \longrightarrow A / L & =0.4\end{aligned}$

$\rightarrow A / L=0.6$

$\leftarrow A / L=0.8$

$\rightarrow A / L=1.0$

(b)

(a)

FIGURE 11: Strain distribution diagram of the joint slot. (a) Logarithmic strain components of the joint slot. (b) Equivalent plastic strain of the joint slot. 


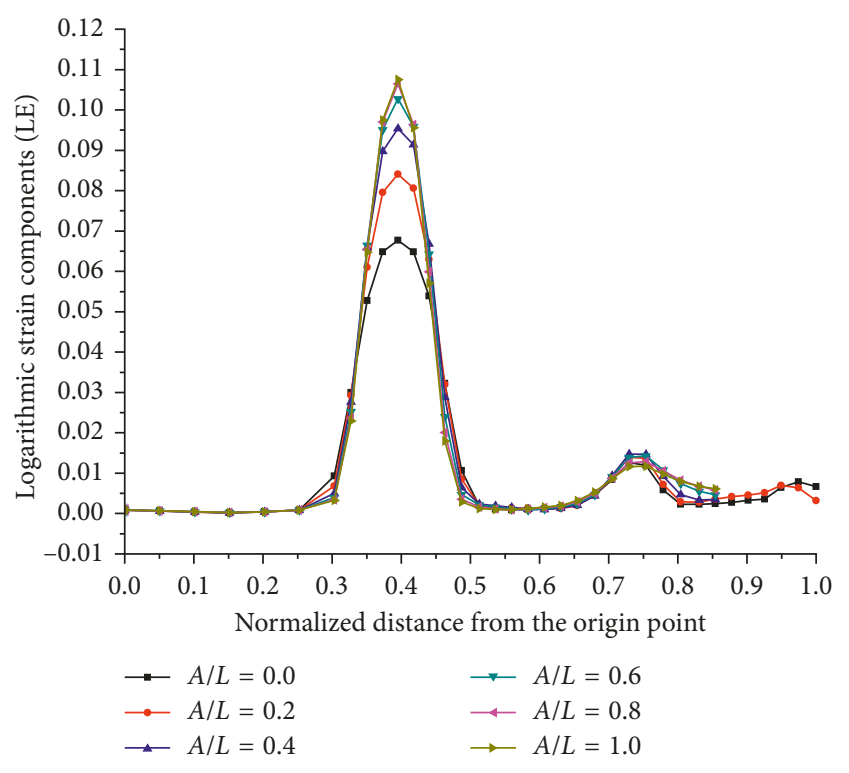

(a)

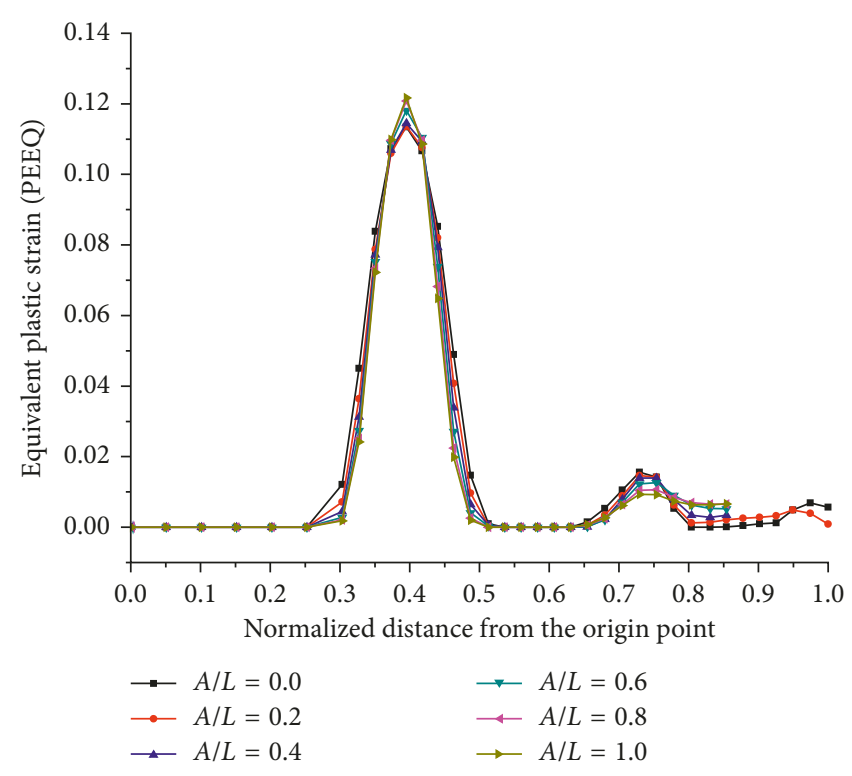

(b)

FIGURE 12: Strain distribution diagram of the wedge-shaped part of the joint. (a) Logarithmic strain components of the wedge-shaped part of the joint. (b) Equivalent plastic strain of the wedge-shaped part of the joint.

(1) Stress Analysis of the Plug-In Joint Slot. The equivalent stress, $x$-axis stress, $y$-axis stress, and $z$-axis stress data of the six monitoring points in the plug-in joint slot are extracted, and the corresponding stress curves are drawn in Figures 14 and 15 .

Figure 14(a) shows the equivalent stress distribution curve of six monitoring paths of the joint slot. In this part, the change regulation of equivalent stress is analyzed using the path $A / L=0$ as an example. As shown in the diagram, the maximum equivalent stress of the joint slot is $300 \mathrm{MPa}$, and the Mises stress at the starting point is 0. Furthermore, the equivalent stress linearly increases when the monitoring point is located in the $0 \sim 0.2$ normalized distance area. At $x=0.2$, that is, at the left boundary point of the assembly connection area, the equivalent stress of the monitoring path reaches its maximum value of $300 \mathrm{MPa}$. The stress remains at its maximum value when the monitoring point is in the 0.2 0.4 normalized distance area. Then, as the monitoring point continues to approach the end of the path, the stress drops sharply to $50 \mathrm{MPa}$ and increases slightly to the local maximum value of $90 \mathrm{MPa}$. Finally, the equivalent stress continuously decreases and eventually reaches zero at a normalized distance of $x=1.0$. According to the analysis of the other five stress curves, the stress changes along different paths are similar. Unlike the curves $A / L=0$ and $A / L=1$, the four curves of $A / L=0.2,0.4,0.6$, and 0.8 have local minimum values when the monitoring point is located in the $0.2 \sim 0.4$ normalized distance area, indicating a local low stress region in the middle of the side face of the joint slot, and it is obviously smaller than the other parts around it.

Figure 14(b) shows the S11 stress distribution curve of the joint slot. The S11 stress of the monitoring points of the six paths is less than 0 , and the minimum value is $-200 \mathrm{MPa}$, which indicates that the joint slot mainly bears the pressure along the $x$-axis direction, and the connecting part of the joint withstands the strongest pressure effect.

Figure 15(a) shows the S22 stress distribution curves of the joint slot. Taking the path $A / L=0$ as an example, the S22 stress value is always positive when the monitoring point is in the $0 \sim 0.2$ normalized distance area, and the maximum value is $290 \mathrm{MPa}$, indicating that this part of the joint slot mainly bears the pull effect in the $y$-axis direction. However, the stress value becomes negative when the monitoring point moves into the 0.2 0.4 normalized distance area, and the minimum value is $-310 \mathrm{MPa}$, indicating that this part of the joint slot mainly bears the pressure action in the $y$-axis direction. Furthermore, when the monitoring points are between 0.4 and 1.0, the stress value quickly increases to $290 \mathrm{MPa}$ and then slowly decreases to 0, which shows that this part of the joint slot mainly bears the pull effect in the $y$ axis direction. For other paths, the S22 stress changing regulations of paths $A / L=0.2$ and $A / L=0.4$ are similar to those of $A / L=0$, while the change rule of paths $A / L=0.6$, $A / L=0.8$, and $A / L=1.0$ is contrary to the variation of the path $A / L=0$.

Figure 15(b) shows the S33 stress distribution of the joint slot. By analyzing the variation of the six curves in the graph, we determine that the S33 stress is positive when the monitoring point is in the $0.18 \sim 0.2$ and $0.4 \sim 0.48$ normalized distance areas. In addition, the S33 stress remains negative when the monitoring point is in the $0.2 \sim 0.4$ normalized distance area, and a minimum value of $-400 \mathrm{MPa}$ occurs, indicating that this part of the joint slot mainly bears the pressure effect in the $z$-axis direction. Furthermore, the stress value is 0 when the monitoring point is located in the $0 \sim 0.18$ and $0.48 \sim 1.0$ normalized distance areas, indicating that this part of the joint slot does not have any forces acting on it in the $Z$-direction. 


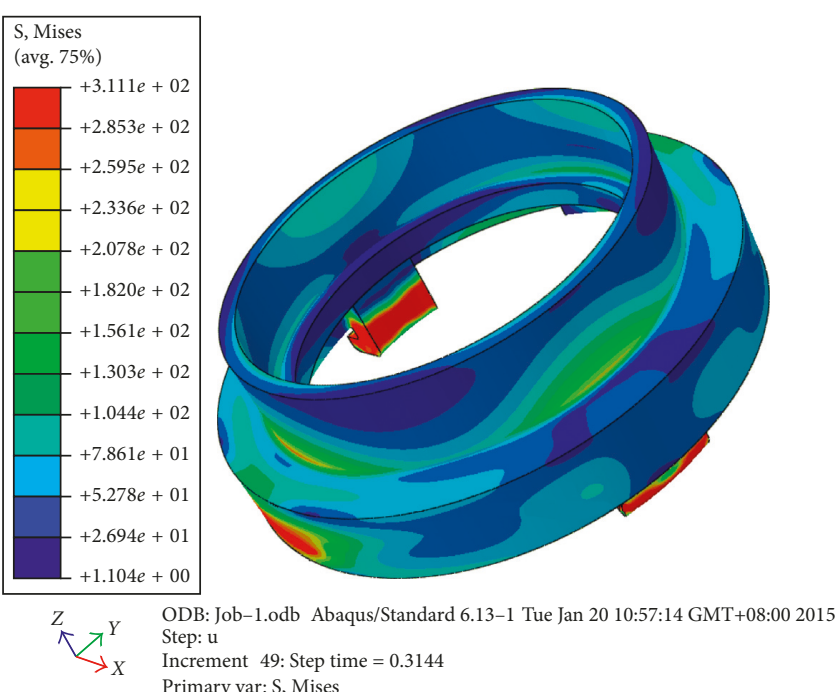

(a)

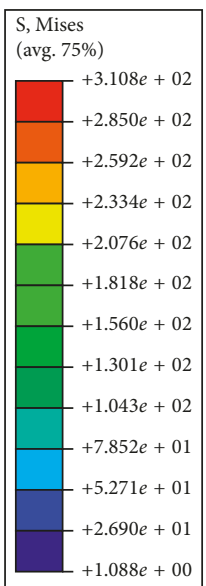

ODB: Job-1.odb Abaqus/Standard 6.13-1 Tue Jan 20 10:57:14 GMT+08:00 2015

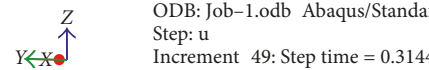
Primary var: $\mathrm{S}$, Mises

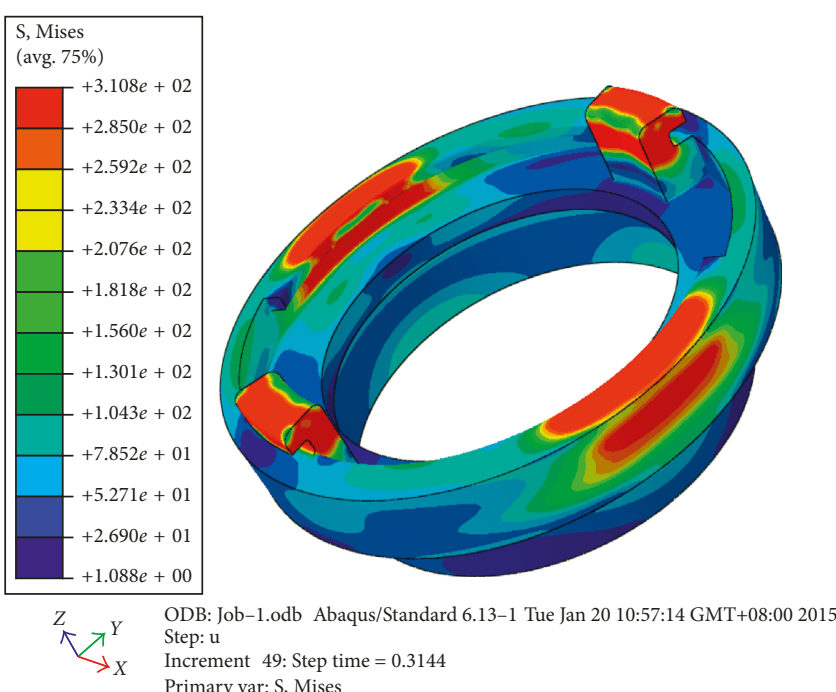

(b)

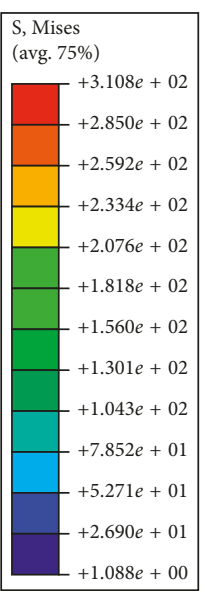

ODB: Job-1.odb Abaqus/Standard 6.13-1 Tue Jan 20 10:57:14 GMT+08:00 2015 Step: u

Increment 49 : Step time $=0.3144$

Primary var: $\mathrm{S}$, Mises

(c)

(d)

FIgURE 13: Stress distribution map of each part of the joint. (a) Stress distribution map of the fixed end. (b) Stress distribution map of the movable end. (c) Sectional stress distribution diagram of the wedge-shaped part of the joint. (d) Sectional stress distribution diagram of the joint slot.

(2) Stress Analysis of the Wedge-Shaped Part of the Joint. The equivalent stress, $x$-axis stress, $y$-axis stress, and $z$-axis stress data of the six monitoring points in the wedgeshaped part of the joint are extracted, and the corresponding stress curve is drawn in Figures 16 and 17. To better analyze the stress distribution of the wedge-shaped part of the joint, the stress distribution curve of the path $A / L=0$ has been taken as an example. In Figure 16(a), the curve of the equivalent stress of the wedge part is approximately a wave shape, and the maximum equivalent stress value of the monitoring point on the entire path is $300 \mathrm{MPa}$. At the bottom end of the wedge, where the monitoring point is located in the $0 \sim 0.2$ normalized distance area, the strain is substantially less than $50 \mathrm{MPa}$. When the monitoring point moves from the bottom of the wedge-shaped part to the middle starting position, that is, the normalized distance of the monitoring point is in the range of $0.2 \sim 0.3$, the equivalent stress value increases rapidly and reaches a maximum value of $300 \mathrm{MPa}$ when the normalized distance is 0.3 . When the monitoring point moves into the $0.3 \sim 0.45$ normalized distance area, the stress maintains the maximum value of $300 \mathrm{Mpa}$, indicating that the stress at the top surface of the wedge part is highly concentrated. The main reason for this phenomenon is that the movable end of the assembly is tightly connected to the fixed end before being subjected to drawing action. When the load applied to the force end increases, the load is transmitted to the weak parts of the assembly, which are the wedge-shaped part of the joint and the connecting position of the joint slot. Then, as the monitoring point continues to move toward the end of the path, the equivalent stress value decreases rapidly and reaches a local minimum value of $180 \mathrm{Mpa}$ at a normalized distance of 0.6 and then rapidly increases to a maximum value of $300 \mathrm{MPa}$. By analyzing the 


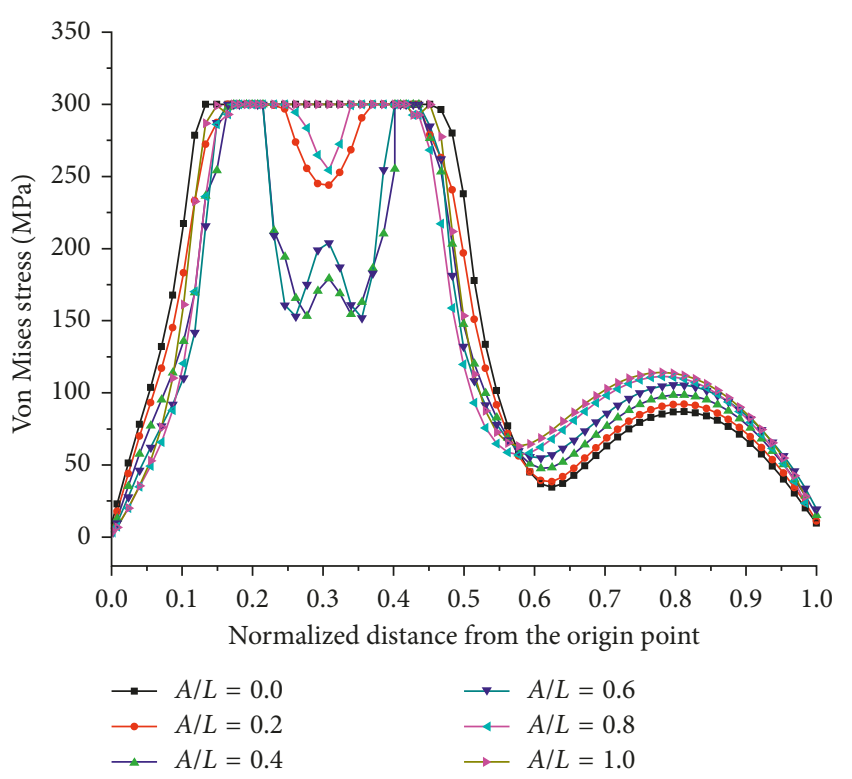

(a)

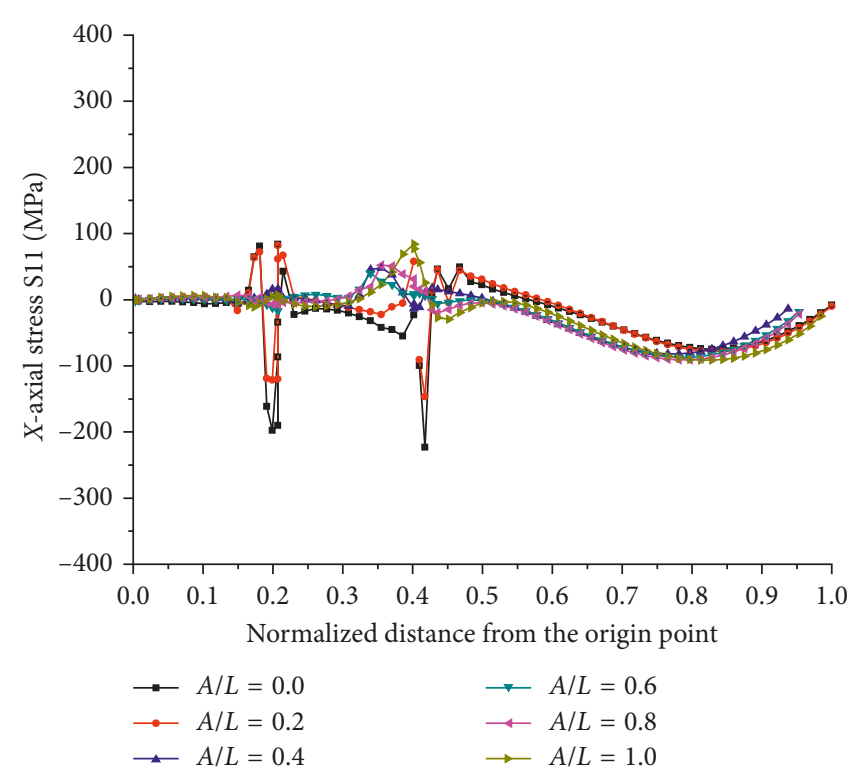

(b)

FIgURE 14: Mises stress and S11 stress distribution curves of the joint slot. (a) Equivalent stress distribution curve. (b) X-axial stress distribution curve.

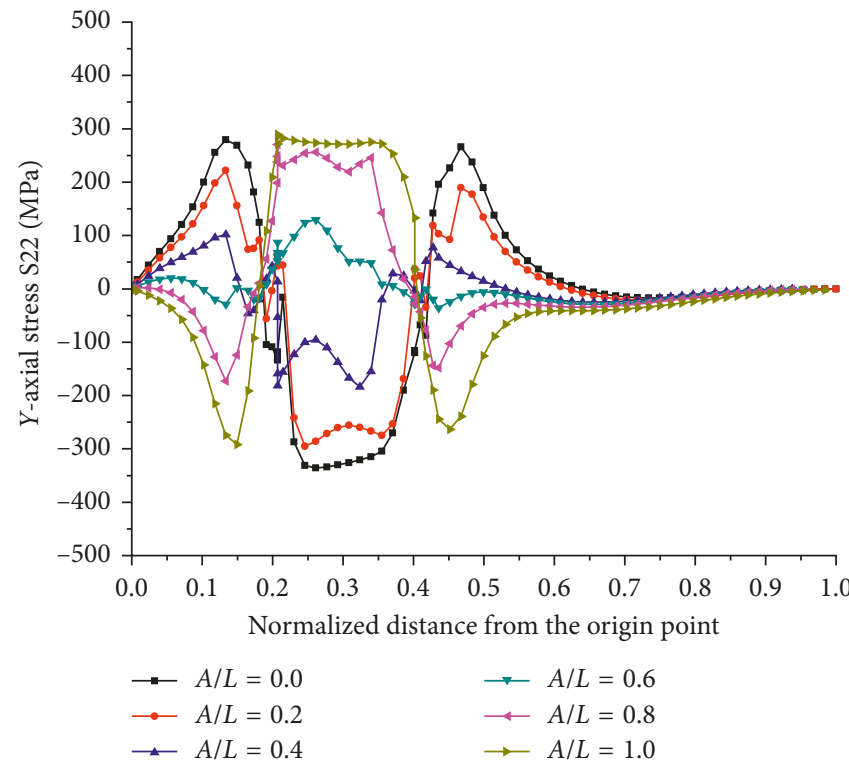

(a)

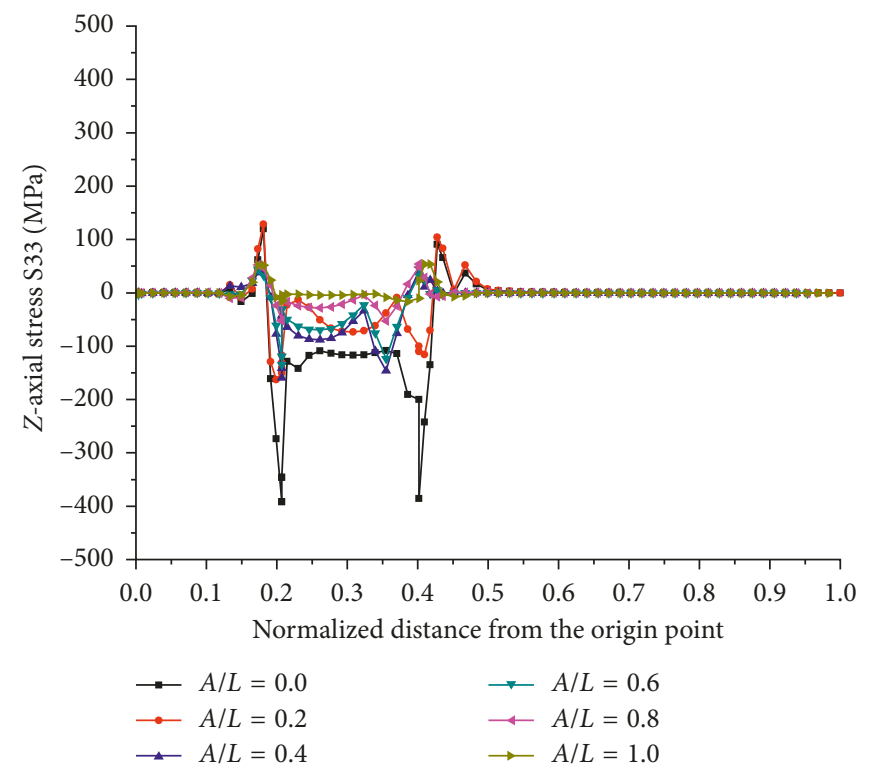

(b)

Figure 15: S22 stress and S33 stress distribution curves of the joint slot. (a) Y-axial stress distribution curve. (b) Z-axial stress distribution curve.

curves of the other five paths, it can be seen that the variation rules of different paths are similar, and the local minimum value of the equivalent stress decreases as the monitoring path translates to the middle position of the wedge part; thus, the wedge has a low stress region in the transverse direction.

Figure 16(b) represents the S11 stress distribution of the wedge-shaped part of the joint. Taking the path $A / L=0$ as an example, it can be seen that, at the bottom of the wedge part, that is, the normalized distance is in the range of 0 to 0.3 , the $S 11$ stress is approximately zero, indicating that this part is not subjected to tensile or compressive stresses in the $x$-axis direction. When the monitoring point is located in the 0.3 0.4 normalized distance area, the S11 stress decreases linearly and reaches a minimum value of $-50 \mathrm{MPa}$ at a normalized distance of 0.4 . As the monitoring point continues to move toward the top position, the S11 stress value increases slightly and reaches a maximum value of $25 \mathrm{MPa}$ at a normalized distance of 0.6 and remains negative afterward, indicating that the top wedge 


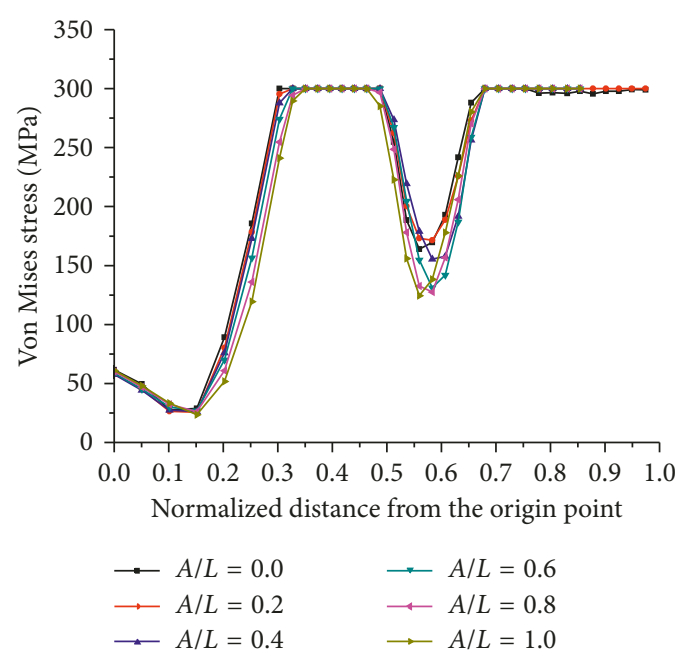

(a)

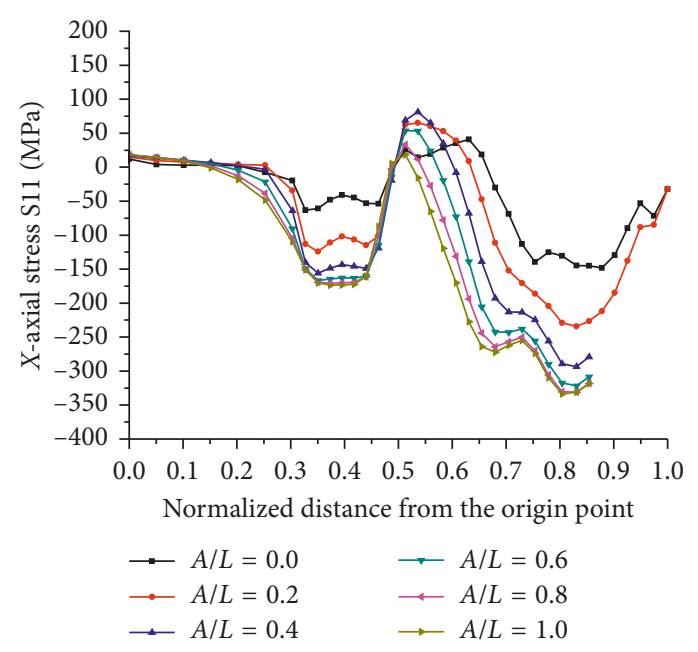

(b)

FIGURE 16: Mises stress and S11 stress distribution curves of the wedge-shaped part of the joint. (a) Equivalent stress distribution curve. (b) $\mathrm{X}$-axial stress distribution curve.

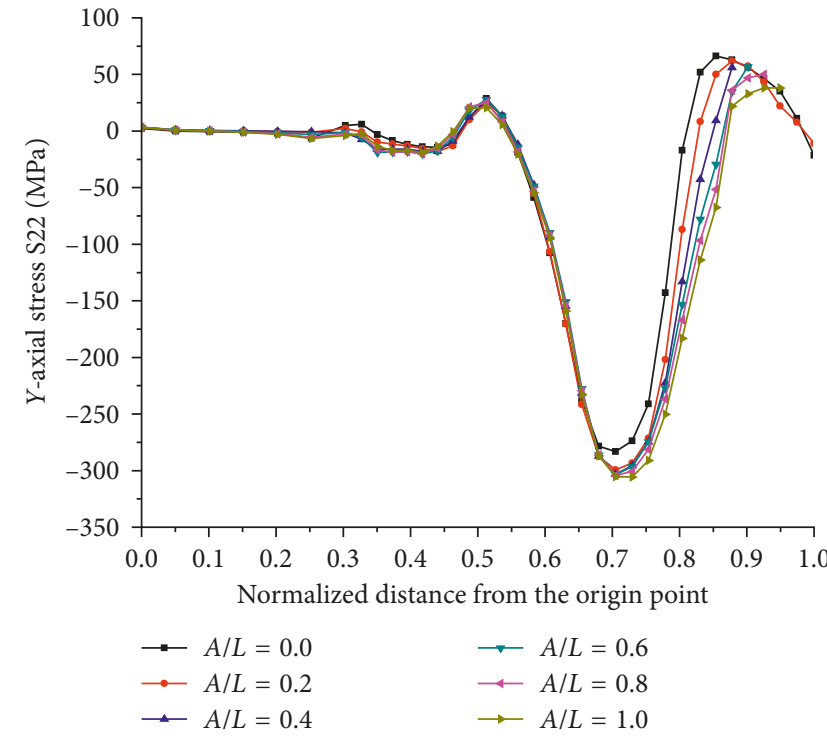

(a)

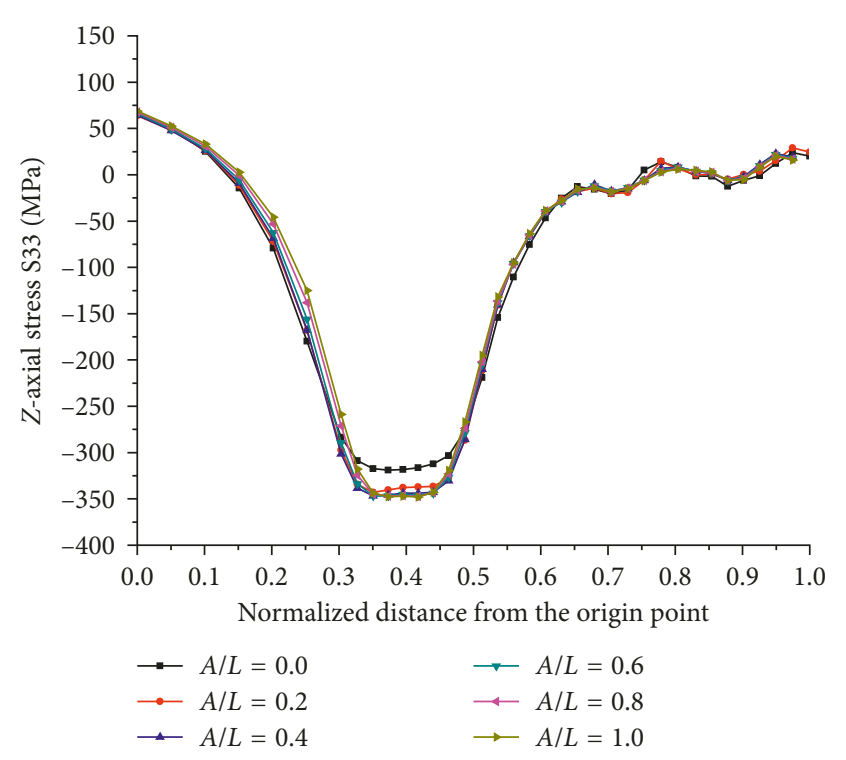

(b)

Figure 17: S22 stress and S33 stress distribution curves of the wedge-shaped part of the joint. (a) Y-axial stress distribution curve. (b) Z-axial stress distribution curve.

is primarily responsible for compressive stress in the $y$-axis direction.

Figure 17(a) shows the Y-axial stress distribution curve of the wedge part. The S22 value is mostly negative from the bottom of the wedge to the top position, indicating that this part mainly bears compressive stress in the $y$-axis direction. The stress reaches a minimum value when the normalized distance is 0.7. The S22 stress value of the monitoring point increases linearly between normalized distances of $0.7 \sim 0.9$, and a maximum value of $50 \mathrm{MPa}$ occurs at a normalized distance of 0.85 . Furthermore, the stress value decreases to zero. Figure 17(a) represents the Z-axial stress distribution curve of the wedge part. Starting from the bottom of the wedge part, the $S 33$ stress starts to decrease from an initial value of $75 \mathrm{MPa}$ and reaches a minimum value of $-325 \mathrm{MPa}$ at a normalized distance of 0.4 . Then, as the monitoring point continues to move toward the end of the monitoring path, the S33 stress value continually increases and reaches a value of 0 .

(3) Stress Analysis of Slices with Different Thickness. From the previous stress analysis, we determined that there is a low stress region in the middle part of the wedge. To further analyze the stress distribution of the wedge during the 


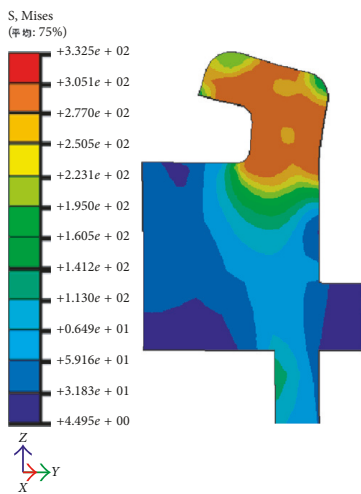

(a)

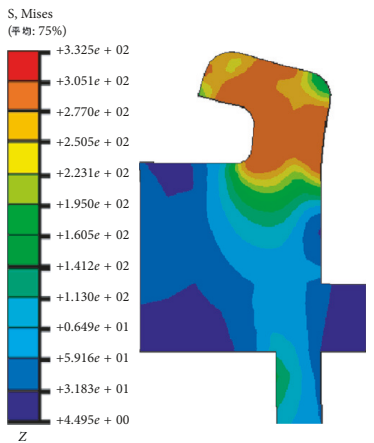

(c)

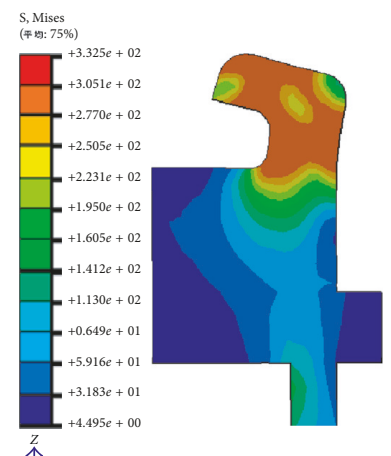

(e)

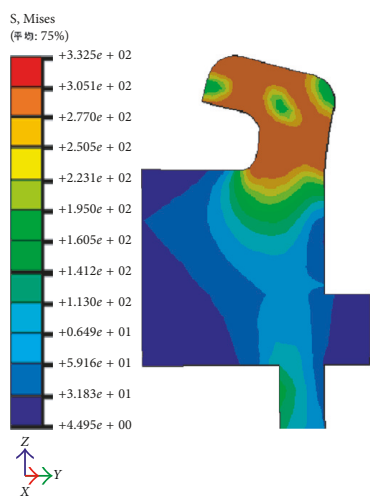

(g)

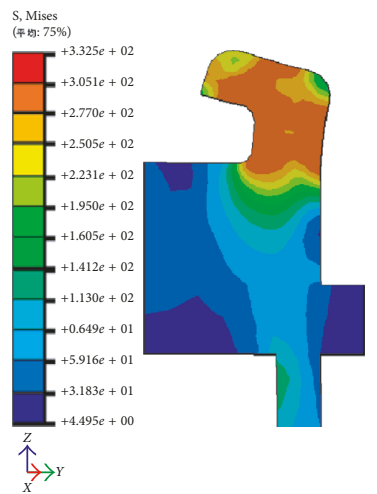

(b)

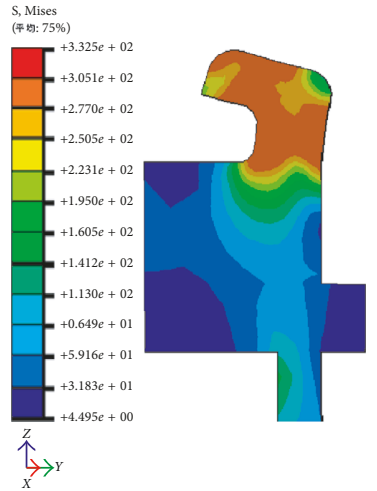

(d)

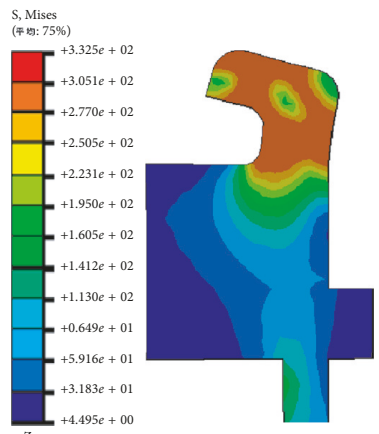

(f)

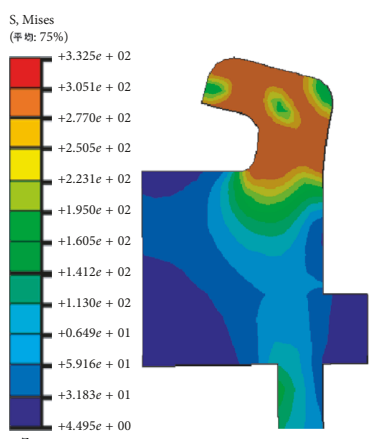

(h)

Figure 18: Continued.

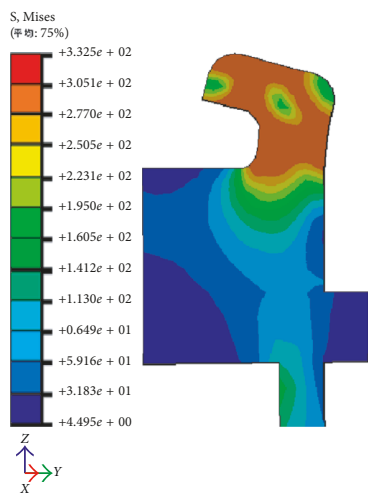

(i)

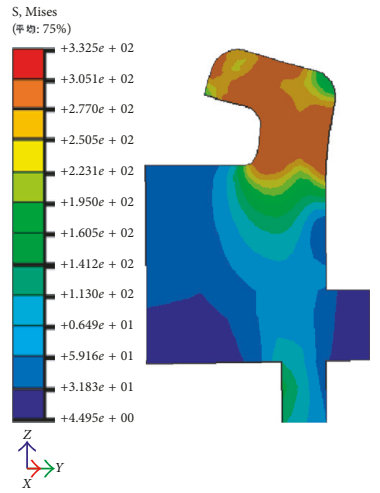

$(\mathrm{k})$

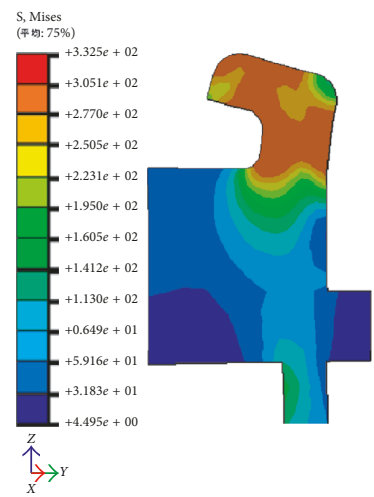

(j)

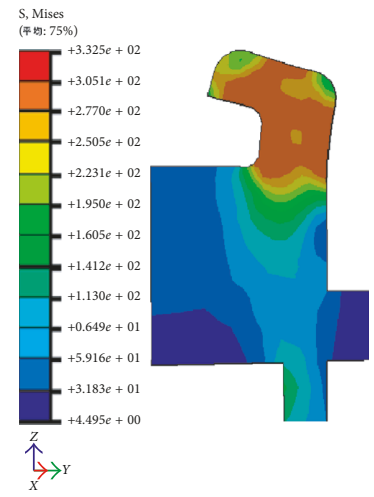

(l)

FIgURE 18: Wedge slices at different positions: (a) $\gamma=66^{\circ}$, (b) $\gamma=68^{\circ}$, (c) $\gamma=70^{\circ}$, (d) $\gamma=72^{\circ}$, (e) $\gamma=74^{\circ}$, (f) $\gamma=76^{\circ}$, (g) $\gamma=78^{\circ}$, (h) $\gamma=80^{\circ}$, (i) $\gamma=82^{\circ}$, (j) $\gamma=84^{\circ}$, (k) $\gamma=86^{\circ}$, and (l) $\gamma=88^{\circ}$.

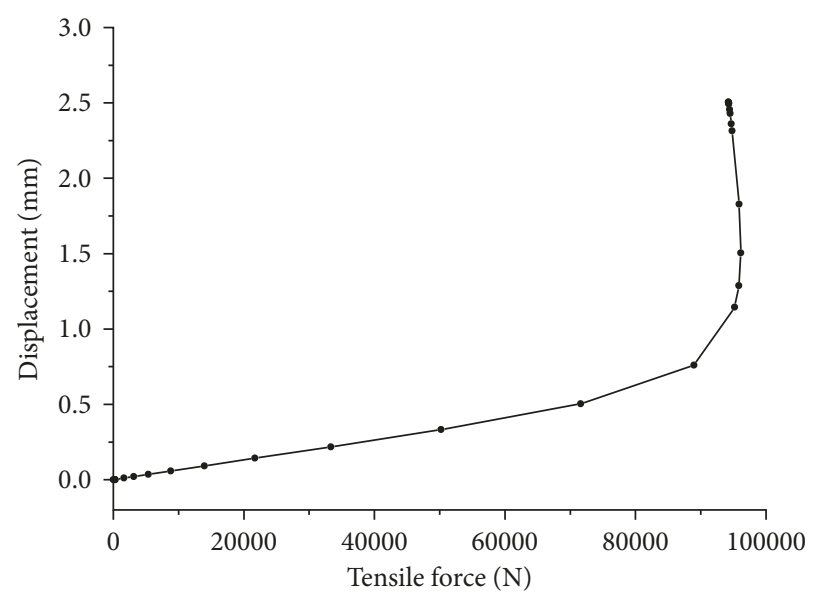

Figure 19: Tension and displacement diagram of the joint.

drawing process, the wedge parts are cut according to a certain angle, and the stress distribution variation of the cross section of the wedge parts is analyzed, as shown in Figure 18. 
TABLE 2: Mechanical properties of different aluminum alloys.

\begin{tabular}{lcc}
\hline Materials & Parameters & Values \\
\hline & Elastic modulus $E(\mathrm{MPa})$ & $0.71 \times 10^{5}$ \\
& $2.8 \times 10^{3}$ \\
Aluminum alloy LY12M & Density $\left(\mathrm{kg} / \mathrm{m}^{3}\right)$ & 0.31 \\
& Poisson's ratio $\mu$ & 300 \\
& Yield strength $\sigma_{0.2}$ & $0.72 \times 10^{5}$ \\
& Elastic modulus $E(\mathrm{MPa})$ & $2.8 \times 10^{3}$ \\
Aluminum alloy LY12CZ & Density $\left(\mathrm{kg} / \mathrm{m}^{3}\right)$ & 0.33 \\
& Poisson's ratio $\mu$ & 380 \\
& Yield strength $\sigma_{0.2}$ & $0.74 \times 10^{5}$ \\
Aluminum alloy LC4-CS & Elastic modulus $E(\mathrm{MPa})$ & $2.8 \times 10^{3}$ \\
& Density $\left(\mathrm{kg} / \mathrm{m}^{3}\right)$ & 0.33 \\
& Poisson's ratio $\mu$ & 550 \\
\hline
\end{tabular}

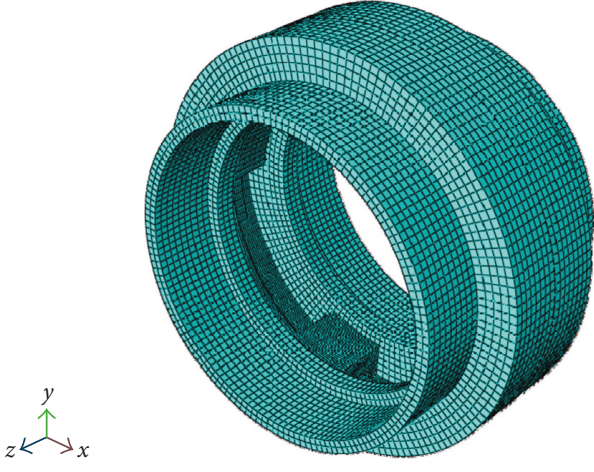

(a)

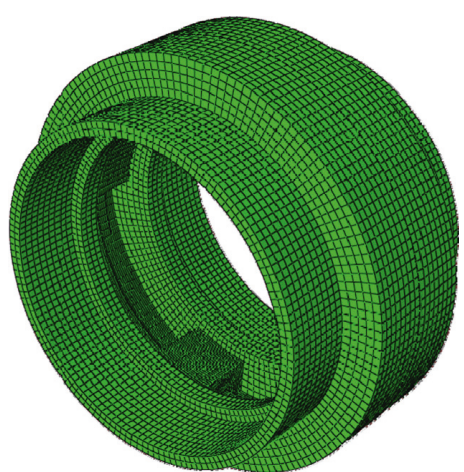

(b)

Figure 20: Joint models with different materials. (a) Aluminum alloy LY12CZ joint model. (b) Aluminum alloy LC4-CS joint model.

From Figure 18, the stress distribution regulation of the slices at different thickness positions of the wedge part is nearly identical. The top position of the wedge has a high degree of stress concentration, and from top to bottom, the stress of the wedge cross section appears to reduce gradually. Beginning at the cross section of $\beta=66$ degrees, the low stress region appears at the top of the wedge, and the low stress region increases as the cross section moves toward the middle position of the wedge. As the cross section is farther from the middle position, the low stress region gradually decreases, indicating that the lateral stress of the wedge part of the joint is higher, while the internal stress of the wedge is lower.

(4) Tensile Strength Analysis of the Joint. The displacement and tension of the reference point RP on the movable ends of the joint are extracted. The tensile displacement curve of the joint is plotted using the tensile force of the $x$-axis and considering the displacement value of the $y$-axis, as shown in Figure 19.

From Figure 19, the limit displacement of the joint during the drawing process is $2.5 \mathrm{~mm}$, and the ultimate tensile force is $91147.4 \mathrm{~N}$. When the load applied to the joint is less than $10000 \mathrm{~N}$, the displacement of the movable end of the joint is approximately zero. As the load exceeds $10000 \mathrm{~N}$, the displacement of the movable end increases, and the relationship between the tension and the displacement is linear when the load is between $10000 \mathrm{~N}$ and $80000 \mathrm{~N}$. When the applied load exceeds $80000 \mathrm{~N}$, the displacement of the joint increases abruptly, and the joint is broken when the displacement reaches $2.5 \mathrm{~mm}$. Accordingly, the ultimate tensile force of the joint is $91147.4 \mathrm{~N}$.

(5) Influence of Material Properties on Strength of the Hose Joint

(1) Model Establishment. To study the change in tensile strength of the hose joint with different materials, the common cast aluminum alloy materials LY12CZ and LC4-CS were selected to establish different finite element analysis models for calculation and comparative analysis with the basic joint model applied with the LY12M material. The mechanical properties of the three materials are shown in Table 2.

The materials with different properties are assigned to basic hose joint models, and the corresponding simulation models are established, as shown in Figure 20.

For finite element analysis models applied with aluminum alloy materials LY12CZ and LC4-CS, the static general analysis step is set, and the geometric nonlinearity function is opened in ABAQUS. The initial incremental step is 0.1 , the minimum analysis step is $1 E-009$, and the maximum incremental step is 10000 . In addition, the contact surface of the assembly hose joint is determined, and the aluminum 


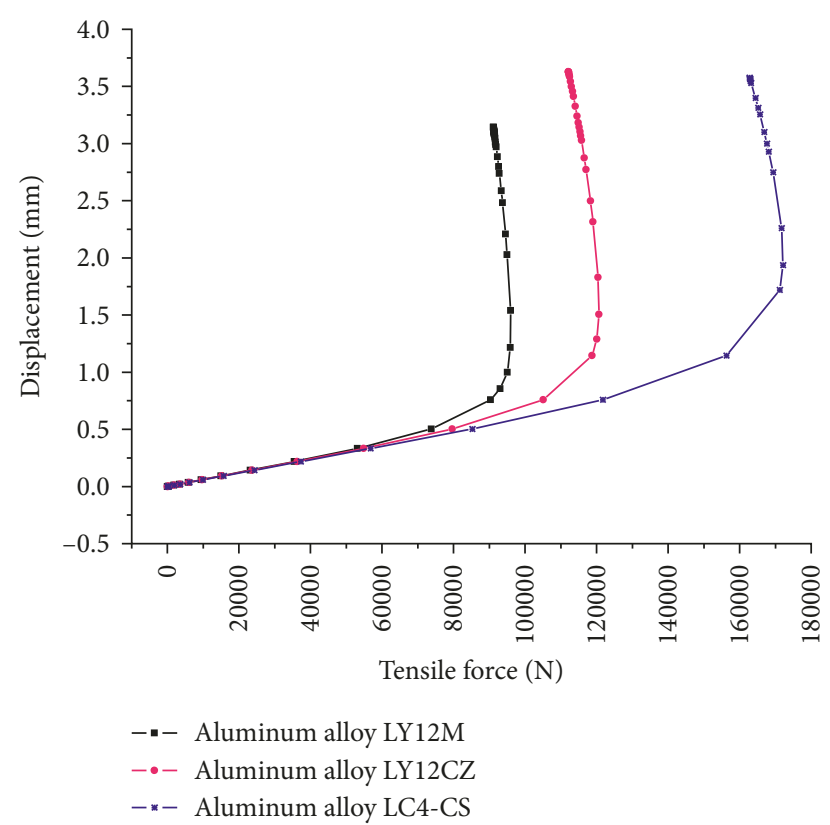

FIgURE 21: Tension and displacement diagram of the joint under different material parameters.

alloy friction coefficient is defined as 0.3 . The divided units are set as reduced integral hexahedral elements. The right side of the joint is set as the movable surface, and the displacement in the $x$-axis and $y$-axis direction is fixed, while the movement in the $z$-axis direction is reserved. Finally, the finite element model is set and submitted to the standard solver in ABAQUS for analysis and calculation.

(2) Calculation Results and Analysis. After calculating the two-material joint finite element models, the displacement and tension force of the reference point RP on the movable ends of the joints are extracted. The tensile displacement curves of the material joints are conducted by plotting the tensile force along the $x$-axis and plotting the displacement along the $y$-axis, and the results are compared and analyzed with the previous results of the joint model applied with aluminum alloy LY12M.

From Figure 21, the variation regulation of the three displacement tension curves is similar. When the tension is less than $10000 \mathrm{~N}$, the displacement of the movable end of the joint is zero, and when the tension applied to the joint continues to increase, the displacement of the movable end of the joint increases gradually from 0 . Compared with aluminum alloy LY12M, the ultimate tensile force of the joint with the aluminum alloy LY12CZ material reaches $112142 \mathrm{~N}$ and increases by $23 \%$. The ultimate tensile force of the joint with the aluminum alloy LC4-CS material reaches $162756 \mathrm{~N}$ and increases by $79 \%$. By analyzing the performance difference of the three materials, it is found that the yield strength of the material has a great influence on the tensile strength of the joint. The main reason is that the material of the entire joint is singular. During the entire pulling process, the increased gap between the wedge part and the joint slot part and the corresponding morphological changes are the result of substantial material yield variation. Therefore, the ultimate tensile strength of the joint can be significantly improved by choosing the material with higher yield strength without changing the geometric size of the joint.

(6) Influence of Center Angle on the Strength of the Hose Joint. As shown in Figure 22, the size of the joint wedge part is defined by the center angle $\beta$. In the basic joint model, the center angle $\beta$ is equal to $23.5^{\circ}$. To analyze the influence of wedge size on the tensile strength of the joint, the joint model with different center angles $\beta$ is established on the premise that the other parts maintain the same size, and the finite element analysis is carried out. The joint models for the different center angles $\beta$ are shown in Table 3 and Figure 22. The ABAQUS software parameter is set in the same way as the previous basic model simulation process.

After calculating the four finite element joint models corresponding to different center angles $\beta$, the displacement and tension of the reference point RP on the movable ends of the joints are extracted. The tensile displacement curve of those joints is conducted by plotting the tensile force along the $x$-axis and plotting the displacement values along the $y$-axis, and the results are compared and analyzed with the previous result of the joint model applied with the center angle $\beta$ equal to $23.5^{\circ}$. The results are presented in Figure 23.

From Figure 23, the variation regulation of the five displacement tension curves is similar. When the tension is less than $10000 \mathrm{~N}$, the displacement of the movable end of the joint is approximately zero, and when the tension applied to the joint continues to increase, the displacement of the movable end of the joint increases gradually from 0 . Compared with the basic joint model with a center angle $\beta=23.5^{\circ}$, the ultimate tensile force of the joint with a center angle $\beta=21.5^{\circ}$ is $84415.5 \mathrm{~N}$, which is approximately $7 \%$ less. When the center angle of the joint is $\beta=22.5^{\circ}$, the ultimate tension is $86866.7 \mathrm{~N}$, which is approximately $5 \%$ less. The ultimate tensile force of the joint with a center angle $\beta=24.5^{\circ}$ reaches $97520.5 \mathrm{~N}$ and increases by $7 \%$. The ultimate tensile force of the joint with a center angle $\beta=25.5^{\circ}$ reaches $98411 \mathrm{~N}$ and increases by $8 \%$. Therefore, by increasing the center angle of the wedge part of the joint, that is, increasing the contact area between the wedge part and the slot of the joint, the tensile strength of the joint can be improved.

\section{Experimental Study on Strength Optimization of the Plug-In Oil Hose Joint}

To test the tensile strength of the plug-in hose connector and analyze the specific failure form of the joint during the axial drawing process, a tension experiment of the plug-in hose joint sample was conducted using a $1000 \mathrm{kN}$ microcomputer-controlled servohydraulic universal testing machine and compared with the relevant results of the numerical simulation. 


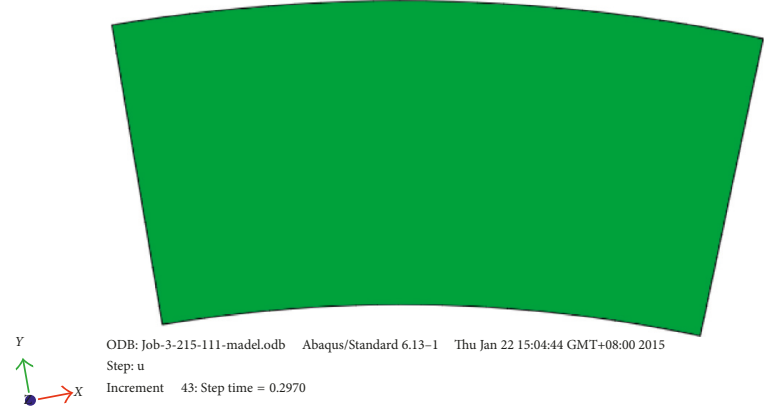

(a)

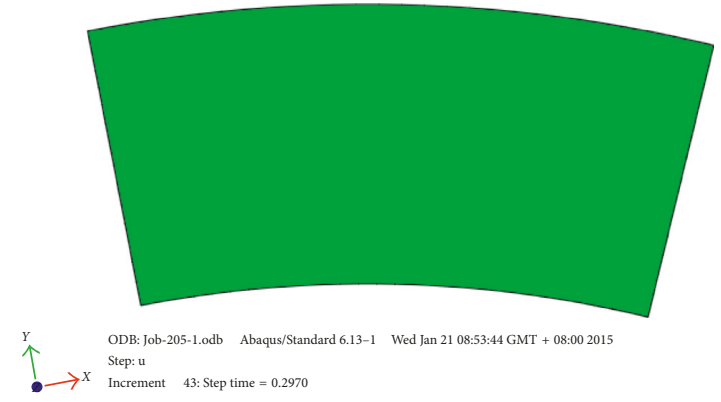

(c)

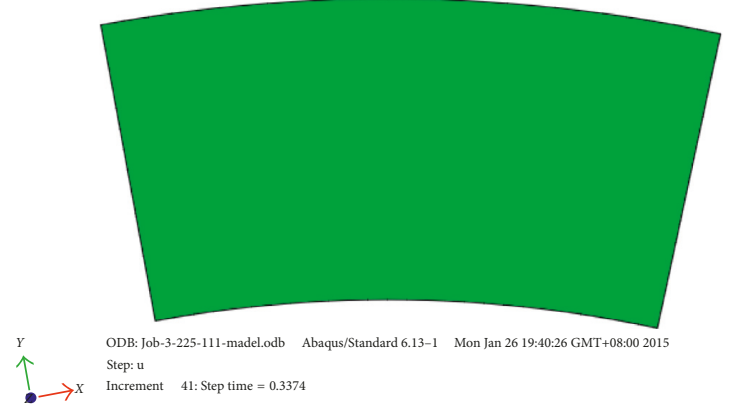

(b)

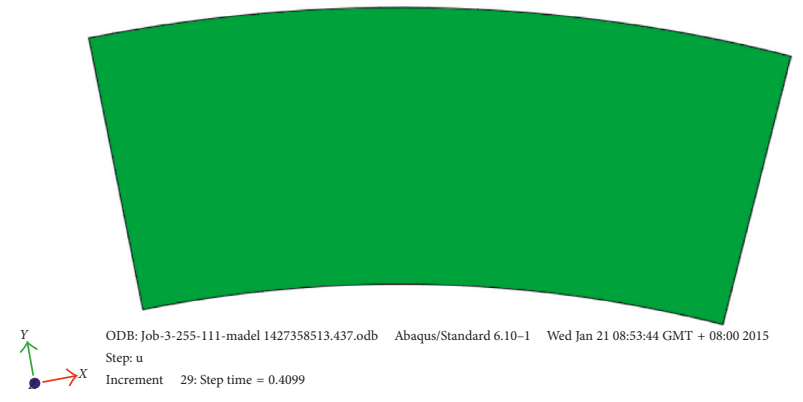

(d)

FIGURE 22: Sectional view of different sizes of the wedge-shaped part of the joint: (a) $\beta=21.5^{\circ}$, (b) $\beta=22.5^{\circ}$, (c) $\beta=24.5^{\circ}$, and (d) $\beta=25.5^{\circ}$.

TABle 3: Hose joint with different center angles.

\begin{tabular}{lccccc}
\hline Sequence number & 1 & 2 & 3 & 4 & 5 \\
\hline Center angle $\beta$ & $21.5^{\circ}$ & $22.5^{\circ}$ & $23.5^{\circ}$ & $24.5^{\circ}$ & $25.5^{\circ}$ \\
\hline
\end{tabular}

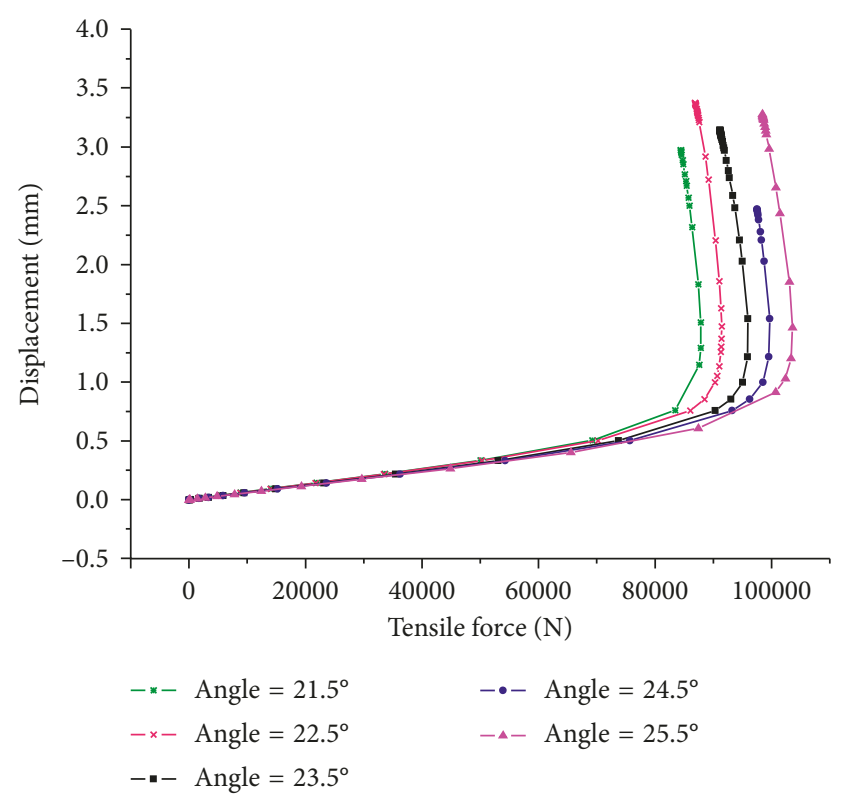

Figure 23: Tension and displacement diagram of the joint corresponding to different center angles.

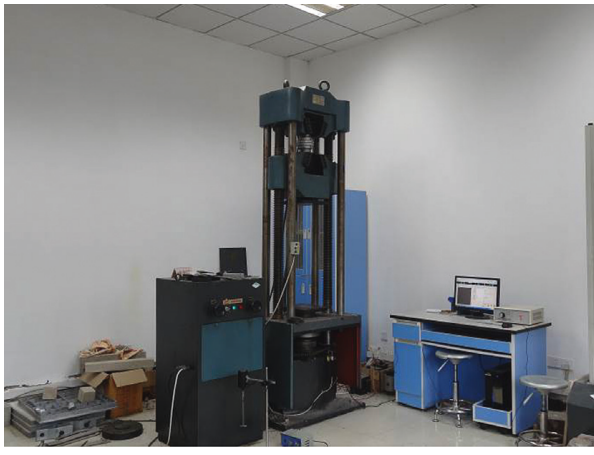

FIGURE 24: $1000 \mathrm{kN}$ microcomputer-controlled servohydraulic universal testing machine.

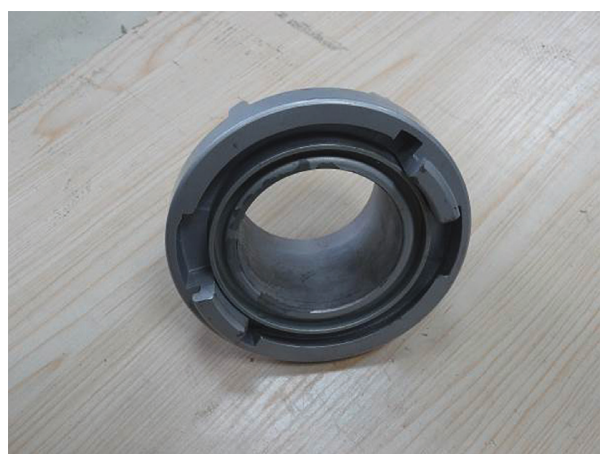

FIGURE 25: Front view of the joint. 


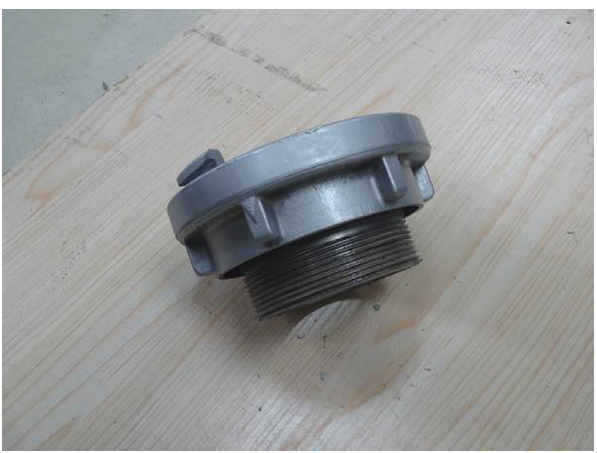

FIGURE 26: Back view of the joint.

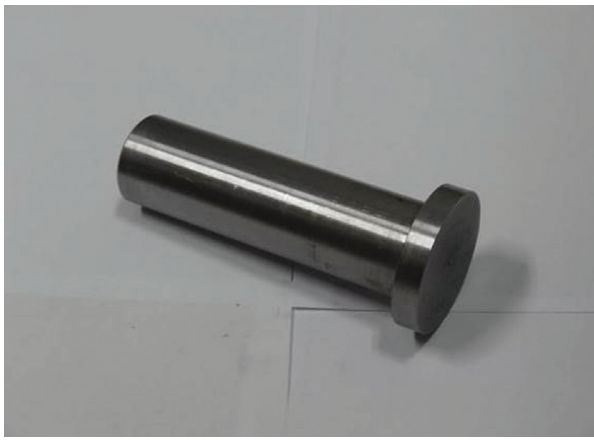

Figure 27: Beam.

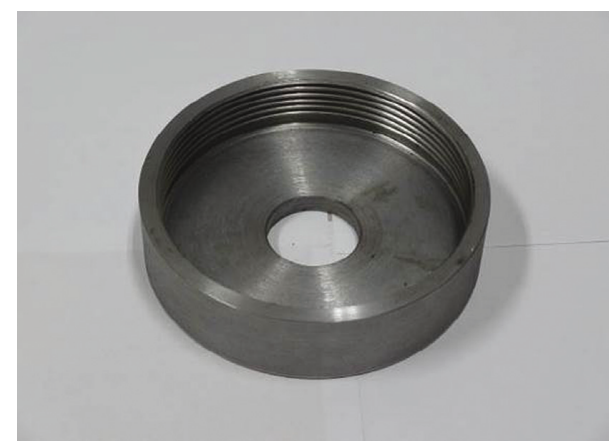

FIgURE 28: Connector.

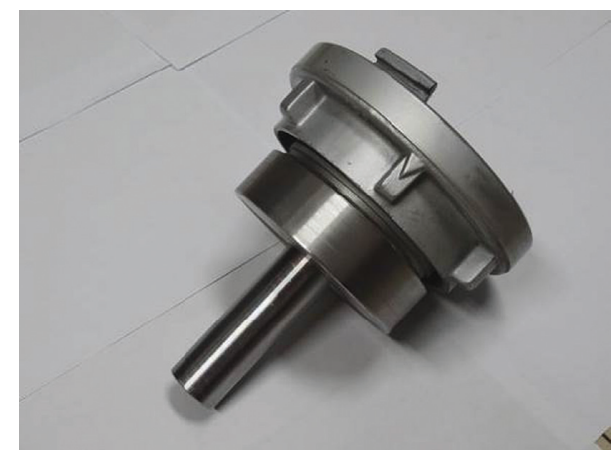

FIgURE 29: Auxiliary fixture assembly.

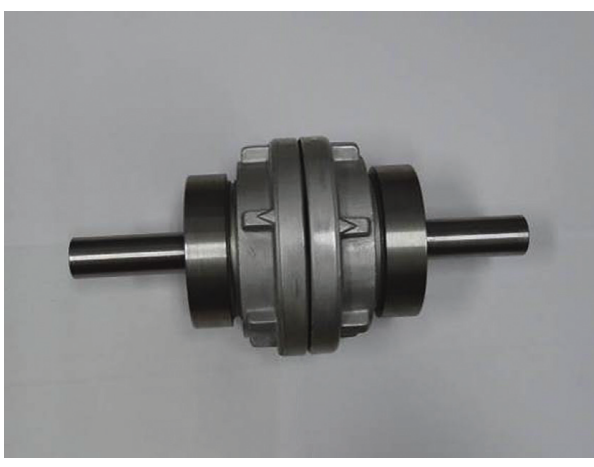

FIGURE 30: Joint assembly.

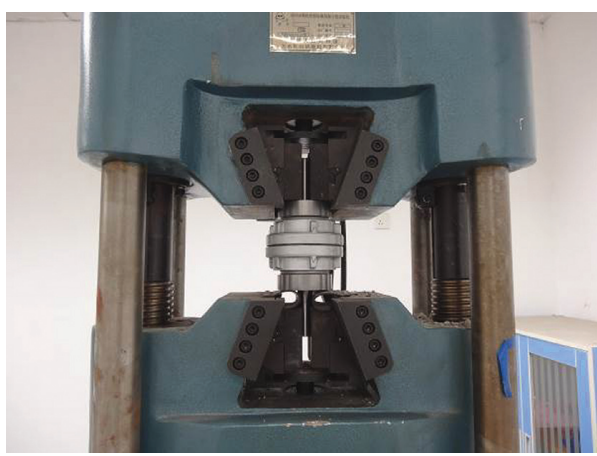

Figure 31: Joint installation.

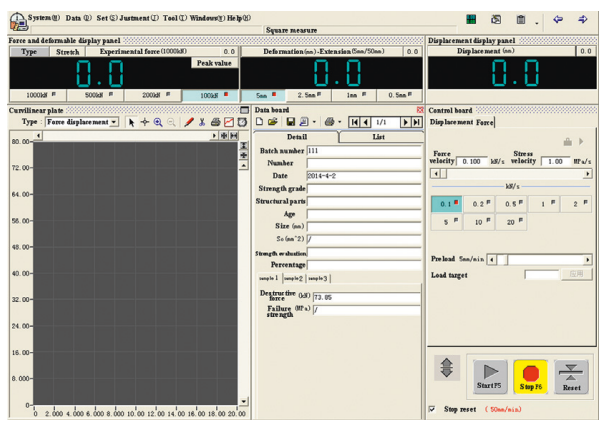

Figure 32: Software initialization.

\subsection{Test Scheme}

5.1.1. Test Instruments and Equipment. The experiment was performed using a $1000 \mathrm{kN}$ microcomputer-controlled servohydraulic universal testing machine, which is shown in Figure 24.

5.1.2. Test Method. According to the basic size of the plug-in hose joint, different aluminum alloy materials have been selected for manufacturing joint samples, which are shown in Figures 25 and 26. In addition, considering the 


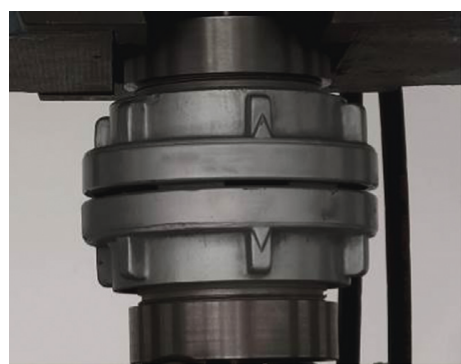

(a)

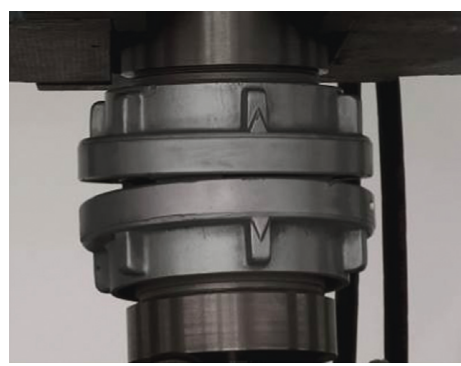

(c)

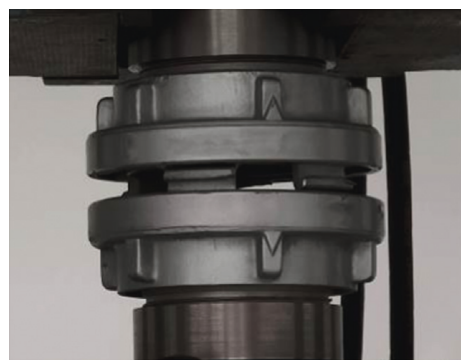

(e)

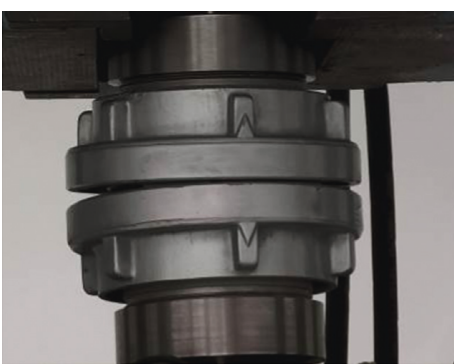

(b)

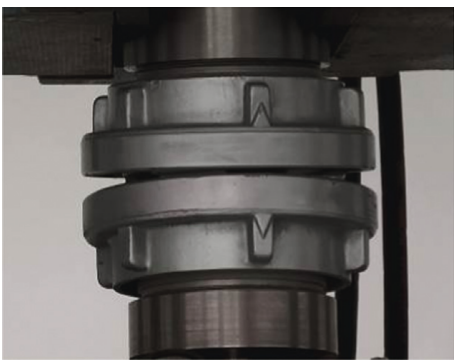

(d)

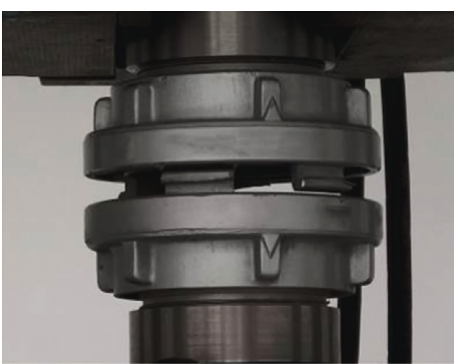

(f)

Figure 33: Joint failure process: (a) $F=71.3 \mathrm{kN}$, (b) $F=71.8 \mathrm{kN}$, (c) $F=72.3 \mathrm{kN}$, (d) $F=72.8 \mathrm{kN}$, (e) $F=73.3 \mathrm{kN}$, and (f) $F=73.8 \mathrm{kN}$.

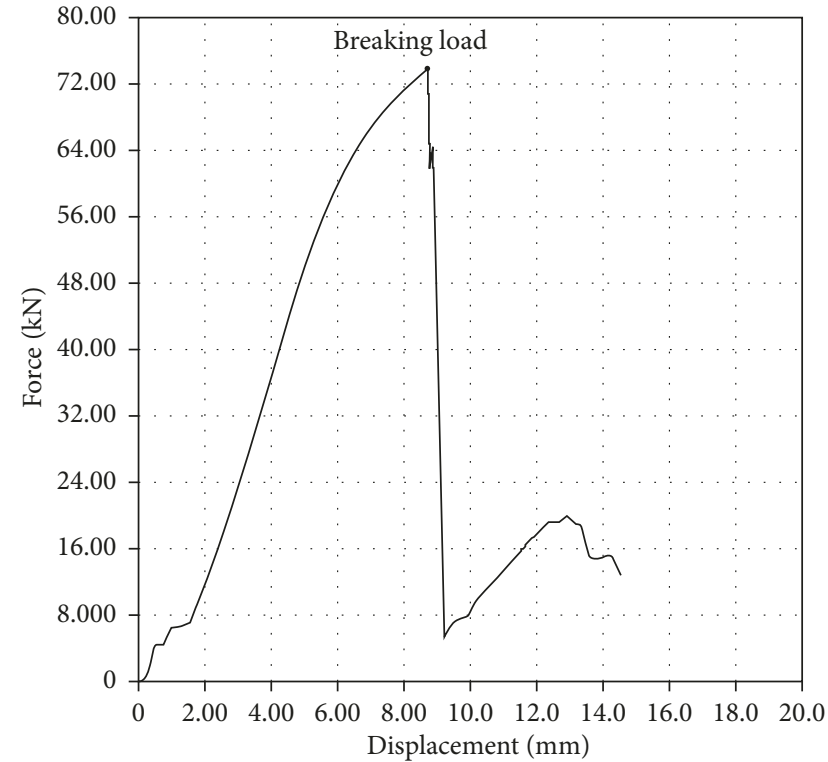

Figure 34: Joint force displacement curve.

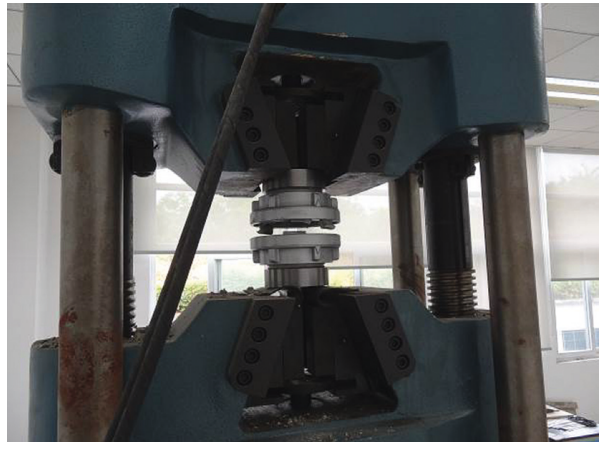

FIgURE 35: Experimental result diagram.

mismatching problem between the universal testing machine and the hose joint and tension requirements of this experiment, carbon steel 235 material was used to make the auxiliary clamp and the connecting head. The beam and connector are shown in Figures 27 and 28. The joint is assembled with the auxiliary furniture to form an auxiliary 


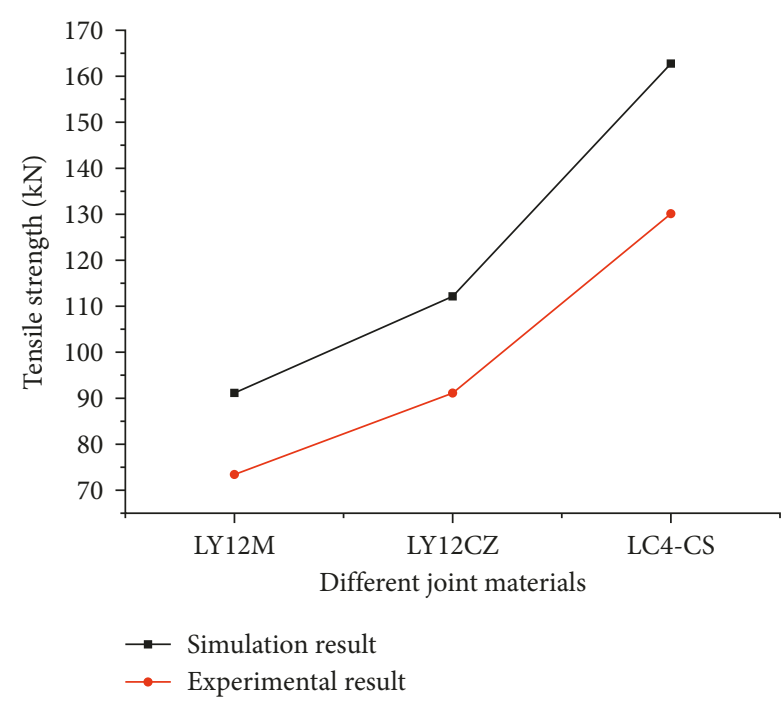

Figure 36: Tensile strength of joints with different materials.

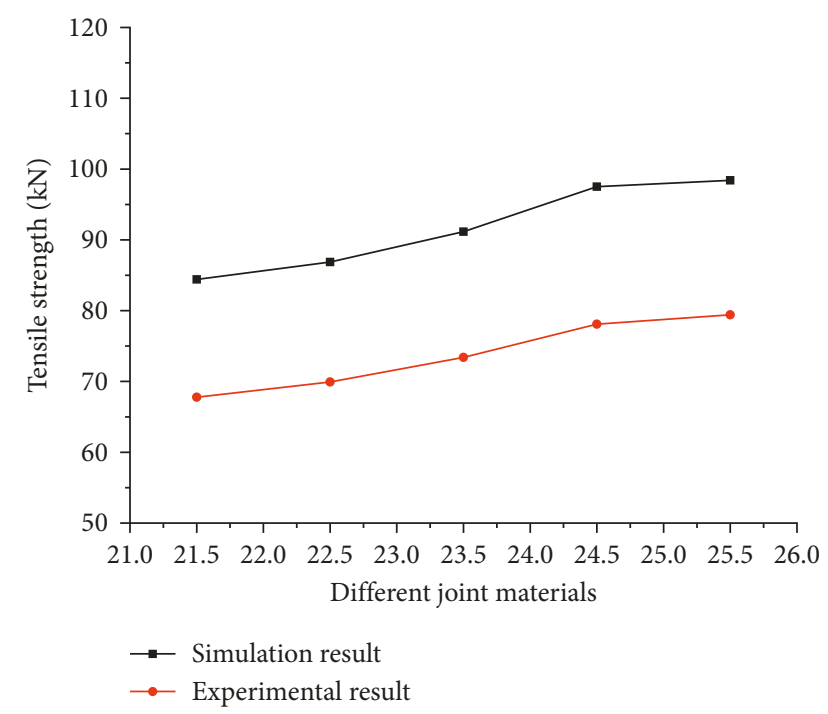

Figure 37: Tensile strength of joints with different center angles.

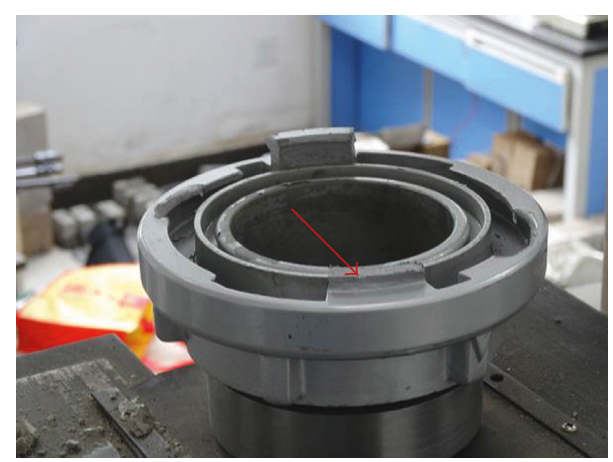

Figure 38: Fracture morphology of the movable end of the joint.

fixture assembly. Next, a paired fitting part of the joint is assembled to form the joint assembly, which is shown in Figures 29 and 30. Then, the auxiliary fixture is tightly

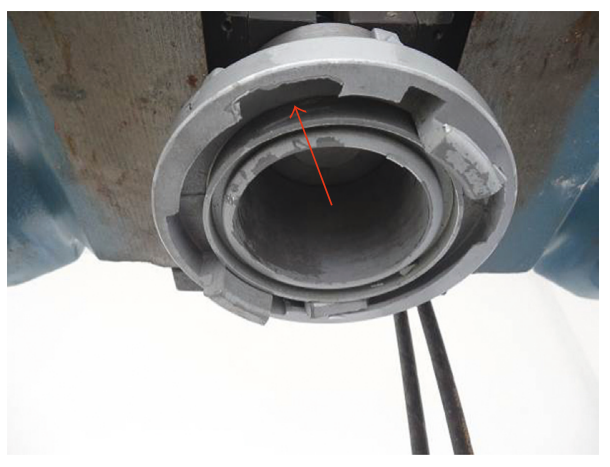

Figure 39: Fracture morphology of the fixed end of the joint.

connected to the test machine chuck, and the distance between the upper and lower chucks of the test machine is adjusted to tighten the joint. Taking this as an initial state, the tensile force of the test machine is continuously increased until the joint is broken. The tensile strength and the form of failure of the joint during the process are analyzed, as shown in Figure 31.

5.1.3. Parameter Settings. Start the test machine computer control, open the application software, and initialize all the parameters. Set the tension acting on the joint to increase gradually at a speed of $0.1 \mathrm{kN} / \mathrm{s}$ until the joint breaks. This process is presented in Figure 32.

5.2. Test Process. The joint drawing process analysis is carried out using the joint with the aluminum alloy LY12M material and $23.5^{\circ}$ center angle as an example. At the initial state, the distance between the movable end of the plug and the fixed end is 0 . As the testing machine begins to produce tension and continues to act on the movable part of the joint, the distance between the moving end of the joint and the fixed end gradually increases, and the relationship between the tension and displacement is linear. When the tension reaches approximately $70 \mathrm{kN}$, the distance between the moving end of the joint and the fixed end increases significantly. At approximately $74 \mathrm{kN}$, the moving end of the joint is separated from the fixed end, that is, the joint is broken. Since the system has automatic data collection, the software interface generates the tensile displacement curve slowly. The drawing process of the joint is shown in Figure 33.

5.3. Test Result and Analysis. During this experiment, the testing machine program automatically records the tension and displacement data and updates relative parameters in the software interface in real time, to analyze the joint displacement tension situation and determine if the joint breaks according to its changing trend.

For the test of the hose joint model with the aluminum alloy LY12M material and a $23.5^{\circ}$ center angle, the tension displacement curve recorded is shown in Figure 34. As shown in Figure 34, the tensile strength of the insert-type hose joint sample was $73.85 \mathrm{kN}$. There is a linear correlation between the tensile forces and the joint displacements, but 
TABLE 4: Tidal data in the experimental sea area.

\begin{tabular}{|c|c|c|c|c|}
\hline Date & High tide time (low tide) & Ebb tide time (full tide) & High tide time (low tide) & Ebb tide time (full tide) \\
\hline July 11 & $3: 12$ & $9: 24$ & $15: 36$ & $21: 48$ \\
\hline July 12 & $4: 00$ & $10: 12$ & $16: 24$ & $22: 36$ \\
\hline July 13 & $4: 48$ & $11: 00$ & $17: 12$ & $23: 24$ \\
\hline July 14 & $5: 36$ & $11: 48$ & $18: 00$ & $0: 12$ \\
\hline July 15 & $6: 24$ & $12: 36$ & $18: 48$ & $1: 00$ \\
\hline July 16 & $7: 12$ & $13: 24$ & $19: 36$ & $1: 48$ \\
\hline July 17 & $8: 00$ & $14: 12$ & $20: 24$ & $2: 36$ \\
\hline July 18 & $8: 48$ & $15: 00$ & $21: 12$ & $3: 24$ \\
\hline July 19 & $9: 36$ & $15: 48$ & $22: 00$ & $4: 12$ \\
\hline July 20 & $10: 24$ & $16: 36$ & $22: 48$ & $5: 00$ \\
\hline July 21 & $11: 12$ & $17: 24$ & $23: 36$ & $5: 48$ \\
\hline July 22 & $12: 00$ & $18: 12$ & $0: 24$ & $6: 36$ \\
\hline July 23 & $0: 48$ & $7: 00$ & $13: 12$ & $19: 24$ \\
\hline July 24 & $1: 36$ & $7: 48$ & $14: 00$ & $20: 12$ \\
\hline July 25 & $2: 24$ & $8: 36$ & $14: 48$ & $21: 00$ \\
\hline July 26 & $3: 12$ & $9: 24$ & $15: 36$ & $21: 48$ \\
\hline July 27 & $4: 00$ & $10: 12$ & $16: 24$ & $22: 36$ \\
\hline July 28 & $4: 48$ & $11: 00$ & $17: 12$ & $23: 24$ \\
\hline July 29 & $5: 36$ & $11: 48$ & $18: 00$ & $0: 12$ \\
\hline July 30 & $6: 24$ & $12: 36$ & $18: 48$ & $1: 00$ \\
\hline July 31 & $7: 12$ & $13: 24$ & $19: 36$ & $1: 48$ \\
\hline August 1 & $8: 00$ & $14: 12$ & $20: 24$ & $2: 36$ \\
\hline August 2 & $8: 48$ & $15: 00$ & $21: 12$ & $3: 24$ \\
\hline August 3 & $9: 36$ & $15: 48$ & $22: 00$ & $4: 12$ \\
\hline August 4 & $10: 24$ & $16: 36$ & $22: 48$ & $5: 00$ \\
\hline August 5 & $11: 12$ & $17: 24$ & $23: 36$ & $5: 48$ \\
\hline August 6 & $12: 00$ & $18: 12$ & $0: 24$ & $6: 36$ \\
\hline August 7 & $0: 48$ & 7:00 & $13: 12$ & $19: 24$ \\
\hline August 8 & $1: 36$ & $7: 48$ & $14: 00$ & $20: 12$ \\
\hline August 9 & $2: 24$ & $8: 36$ & $14: 48$ & $21: 00$ \\
\hline August 10 & $3: 12$ & $9: 24$ & $15: 36$ & $21: 48$ \\
\hline August 11 & $4: 00$ & $10: 12$ & $16: 24$ & $22: 36$ \\
\hline August 12 & $4: 48$ & $11: 00$ & $17: 12$ & $23: 24$ \\
\hline August 13 & $5: 36$ & $11: 48$ & $18: 00$ & $0: 12$ \\
\hline August 14 & $6: 24$ & $12: 36$ & $18: 48$ & $1: 00$ \\
\hline August 15 & $7: 12$ & $13: 24$ & $19: 36$ & $1: 48$ \\
\hline
\end{tabular}

there is a nonlinear change phase at the beginning of the curve. The main reason is that, at the initial stage, there is a certain gap between the moving end and the fixed end of the joint, which affects the displacement of the moving end of the joint (Figure 35). Figures 36 and 37 show the tensile strength test results based on different aluminum alloy materials and different center angles. Based on these figures, the change regulation of the tensile strength of the joint sample is consistent with the corresponding theoretical analysis result, and the conclusion of the numerical analysis is verified. Therefore, it can be concluded that the strength of the joint can be effectively improved by changing the joint material and increasing the center angle of the joint.

In the previous study, the results showed that the tensile force displacement curves are nearly identical between numerical simulations and experiments. However, the theoretical value of the joint ultimate tension differs from the experimental result; in other words, the test results of the tensile strength of the joint are less than the theoretical values. Several reasons may account for this phenomenon. During the finite element analysis process, it is assumed that

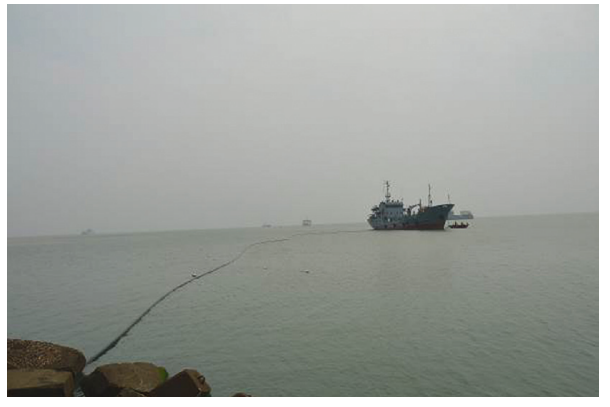

Figure 40: Oil tanker.

the joint does not have initial imperfections and that the material of the joint is isotropic. However, in the actual manufacturing process, defects are inevitable, and the sample material cannot be completely uniform. Furthermore, different manufacturing methods have a greater impact on the strength of the sample. Generally, it is reasonable that the theoretical and experimental values are different, but the difference is within a reasonable range. 


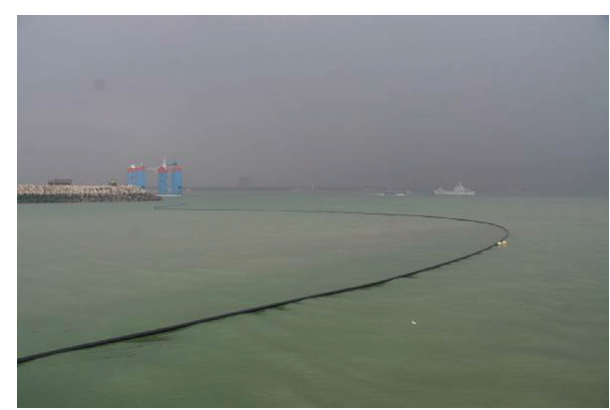

FIGURE 41: Floating pipeline department.

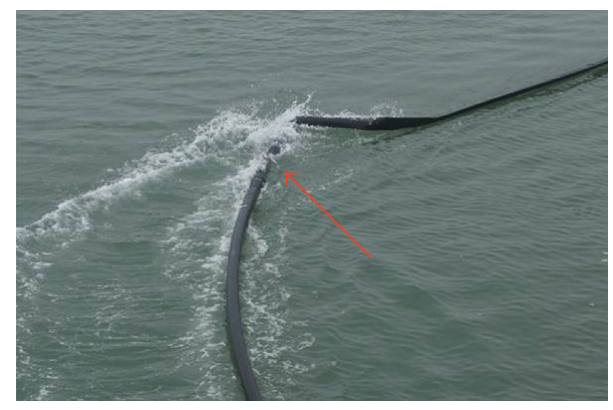

FIGURE 42: Encountering strong currents.

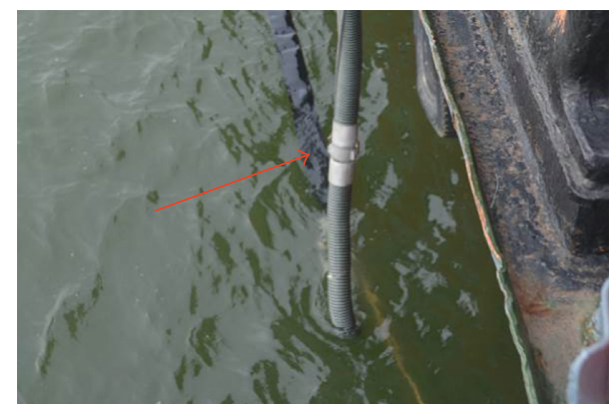

Figure 43: Plug-in joint part.

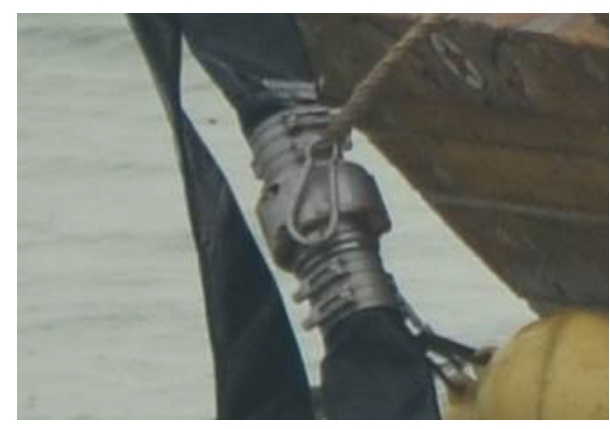

Figure 44: Joint morphology after the test.

5.4. Analysis of Failure Forms of the Hose Joint. It is critical to optimize the joint size and structure and improve the tensile strength of the joint based on studying the failure mode and characteristics of the joint and analyzing the stress distribution of the weak parts of the joint.

Figures 38 and 39 show the broken part of the movable end and the fixed end of the joint. By comparing Figures 38 and 39 , it can be seen that the damage of the moving end is more serious than that of the fixed end. The wedge part of the moving end is pulled off, and the deformation degree of the other wedge part is more serious. The connecting part of the joint slot of the movable end, which is connected with the wedge part of the fixed end, is also broken. The two wedges of the joint fixed end are not pulled through but are seriously deformed, and the joint slots in the fixed end are deformed significantly. Therefore, the connecting position between the wedge part of the joint and the joint slot is the weakest part of the entire assembly. Therefore, to improve the overall tensile strength of the joint, the size of the wedge parts of the joint and joint slot should be optimized, or the material of this part should be changed to a material of higher strength. In addition, the degree of damage of the moving end is more serious than that of the fixed end, mainly because of the test machine force effect on the fixed end through the movable end part. The force transmission mode makes the moving end of the joint more prone to stress concentration.

\section{Strength Reliability Experiment of the Plug- In Joint during Marine Application}

In order to verify the feasibility of theoretical analysis, we carried out an actual oil transportation test on a floating hose system based on improved plug-in joint in Bohai, China. The whole test lasted for 2 months.

6.1. Basic Conditions in the Experimental Sea Area. China Bohai area has been chosen as the test site since this area is wide and the sea waves and currents are representative. The tide in this area is a regular semidiurnal tide. The strong wave is in northeast direction. Its average wave height is $0.7 \mathrm{~m}$, and the maximum wavelength is $3.5 \mathrm{~m}$. The second strong wave is in southeastern direction. Its average wave height is $0.5 \mathrm{~m}$, and the maximum wave height is $3.0 \mathrm{~m}$. The hydrology of the experimental area during the test time is shown in Table 4.

6.2. Experimental Process. In this experiment, the improved plug-in connector is applied to the offshore oil transmission hose for the offshore oil transportation test. In order to test the ultimate tensile strength of the joint as much as possible, the hose fitted with an improved plug-in hose joint has been laid on the sea for two months so as to experience as many different extreme sea conditions as possible. If the hose system can still operate normally under long-term continuous operation, it is proved that the test result of the improved plug-in joint is consistent with the theoretical result. If the joint position of the hose system is damaged due to the load concentration, it is proved that the optimization result of the joint is not perfect enough. Figures $40-43$ show the 
overall form and process of the sea test and point out the specific parts of the joint.

6.3. Experiment Result. Figure 44 shows the final shape of the plug-in joint at the end of the test. In the experimental process, the hose oil delivery system is running normally and there is no oil leakage accident. In addition, we made a careful inspection of the joint, and no deformation or other damage was checked out, which indicates that the improved joint meets the actual use requirements. The experimental results are in agreement with the theoretical simulation results.

\section{Conclusion}

In this paper, the structural characteristics of a plug-in oil hose joint are analyzed, and the mechanical properties are studied using numerical simulations and experiments. The main conclusions of the study are as follows: (1) the strain distribution of the fixed and movable ends of the joint assembly is similar, and the strain mainly occurs on the inside of the wedge-shaped part of the joint and the connecting part with the joint slot. (2) Along with the direction of slot thickness, the maximum strain occurs at the upper surface of the joint slot, and as the thickness increases, the strain gradually decreases. (3) The stress of the wedge-shaped part is mainly concentrated at its top bayonet position, and the stress concentration from the upper part to the bottom part gradually decreases. (4) The stress distribution regulation of slices at different thickness positions of the wedge part is nearly identical. The top position of the wedge has a high degree of stress concentration, and from top to bottom, the stress of the wedge cross section appears to gradually decrease. (5) Compared with aluminum alloy LY12M, the ultimate tensile force of a joint with the aluminum alloy LY12CZ material reaches $112142 \mathrm{~N}$ and increases by $23 \%$. The ultimate tensile force of a joint with the aluminum alloy LC4-CS material reaches $162756 \mathrm{~N}$ and increases by $79 \%$. (6) By increasing the center angle of the wedge part of the joint, that is, increasing the contact area between the wedge part and the slot of the joint, the tensile strength of the joint can be improved. (7) The tensile strength test results of the plugin hose joint are consistent with the theoretical analysis, which verifies the conclusion of the numerical analysis.

\section{Conflicts of Interest}

The authors declare that there are no conflicts of interest regarding the publication of this paper.

\section{Authors' Contributions}

Chang Chen conceived the project and wrote the main manuscript text, Jikun Guo prepared Figures 1-38 and put forward a unique view in representation and analysis, Shifu Zhang subsidized the subject experiment and prepared Tables 1-4, Qixin Zhang designed experiments, Dongmei
Zhang assisted with Illumina sequencing, and Yongjie Niu and Hao Sun analyzed the experimental results. All authors reviewed the manuscript.

\section{Acknowledgments}

This paper is supported in part by the National Key $R \& D$ Program of China (2017YFC0806608), Education Science Fund of the Military Science Institute of Beijing, China (No. 2016JY481), and Chongqing Graduate Scientific Research Innovation Project (No. CYB17148)

\section{References}

[1] P. Lazzarin, V. Milani, and M. Quaresimin, "Scatter bands summarizing the fatigue strength of aluminium alloy bolted joints," International Journal of Fatigue, vol. 19, no. 5, pp. 401-407, 1997.

[2] B. Atzori, P. Lazzarin, and R. Tovo, "From a local stress approach to fracture mechanics: a comprehensive evaluation of the fatigue strength of welded joints," Fatigue and Fracture of Engineering Materials and Structures, vol. 22, no. 5, pp. 369-381, 1999.

[3] P. Lazzarin and P. Livieri, "Notch stress intensity factors and fatigue strength of aluminium and steel welded joints," International Journal of Fatigue, vol. 23, no. 3, pp. 225-232, 2001.

[4] P. Lazzarin, C. M. Sonsino, and R. Zambardi, "A notch stress intensity approach to assess the multiaxial fatigue strength of welded tube-to-flange joints subjected to combined loadings," Fatigue and Fracture of Engineering Materials and Structures, vol. 27, no. 2, pp. 127-140, 2004.

[5] G. Meneghetti and P. Lazzarin, "The peak stress method for fatigue strength assessment of welded joints with weld toe or weld root failures," Welding in the World, vol. 55, no. 7-8, pp. 22-29, 2011.

[6] G. Meneghetti, "The use of peak stresses for fatigue strength assessments of welded lap joints and cover plates with toe and root failures," Engineering Fracture Mechanics, vol. 89, pp. 40-51, 2012.

[7] I. Al Zamzami and L. Susmel, "On the accuracy of nominal, structural, and local stress based approaches in designing aluminium welded joints against fatigue," International Journal of Fatigue, vol. 101, pp. 137-158, 2017.

[8] G. Meneghetti, A. Campagnolo, and D. Rigon, "Multiaxial fatigue strength assessment of welded joints using the peak stress method-part I: approach and application to aluminium joints," International Journal of Fatigue, vol. 101, pp. 328-342, 2017.

[9] W. Song, X. Liu, F. Berto, P. Wang, J. Xu, and H. Fang, "Strain energy density based fatigue cracking assessment of loadcarrying cruciform welded joints," Theoretical and Applied Fracture Mechanics, vol. 90, pp. 142-153, 2017.

[10] W. J. Tomlinson and A. Fullylove, "Strength of tin-based soldered joints," Journal of Materials Science, vol. 27, no. 21, pp. 5777-5782, 1992.

[11] Y. C. Chan, A. C. K. So, and J. K. L. Lai, "Growth kinetic studies of $\mathrm{Cu}-\mathrm{Sn}$ intermetallic compound and its effect on shear strength of LCCC SMT solder joints," Materials Science and Engineering B, vol. 55, no. 1-2, pp. 5-13, 1998.

[12] N. M. Poon, C. M. L. Wu, J. K. L. Lai, and Y. C. Chan, "Residual shear strength of Sn-Ag and Sn-Bi lead-free SMT joints after thermal shock," IEEE Transactions on Advanced Packaging, vol. 23, no. 4, pp. 708-714, 2000. 
[13] S. Ahat, M. Sheng, and L. Luo, "Effects of static thermal aging and thermal cycling on the microstructure and shear strength of Sn95.5Ag3.8Cu0.7 solder joints," Journal of Materials Research, vol. 16, pp. 2914-2921, 2001.

[14] X. Deng, R. S. Sidhu, P. Johnson, and N. Chawla, "Influence of reflow and thermal aging on the shear strength and fracture behavior of Sn-3.5Ag solder/Cu joints," Metallurgical and Materials Transactions A, vol. 36, no. 1, pp. 55-64, 2005.

[15] Y. H. Lee and H. T. Lee, "Shear strength and interfacial microstructure of $\mathrm{Sn}-\mathrm{Ag}-\mathrm{xNi} / \mathrm{Cu}$ single shear lap solder joints," Materials Science and Engineering A, vol. 444, no. 1-2, pp. 75-83, 2007.

[16] S. M. L. Nai, J. Wei, and M. Gupta, "Interfacial intermetallic growth and shear strength of lead-free composite solder joints," Journal of Alloys and Compounds, vol. 473, no. 1-2, pp. 100-106, 2009.

[17] G. Q. Wei, L. Wang, X. Q. Peng, and M. Y. Xue, "Interfacial intermetallic compound growth and shear strength of lowsilver $\mathrm{SnAgCuBiNi} / \mathrm{Cu}$ lead-free solder joints," International Journal of Minerals, Metallurgy, and Materials, vol. 20, no. 9, pp. 883-889, 2013.

[18] T. T. Dele-Afolabi, M. A. A. Hanim, M. Norkhairunnisa, H. M. Yusoff, and M. T. Suraya, "Investigating the effect of isothermal aging on the morphology and shear strength of Sn$5 \mathrm{Sb}$ solder reinforced with carbon nanotubes," Journal of Alloys and Compounds, vol. 649, pp. 368-374, 2015.

[19] S. F. Choudhury and L. Ladani, "Local shear stress-strain response of $\mathrm{Sn}-3.5 \mathrm{Ag} / \mathrm{Cu}$ solder joint with high fraction of intermetallic compounds: experimental analysis," Journal of Alloys and Compounds, vol. 680, pp. 665-676, 2016.

[20] T. Hattori, "A stress singularity parameter approach for evaluating the adhesive strength of single lap joints," JSME International Journal Series I-Solid Mechanics Strength of Materials, vol. 34, no. 3, pp. 326-331, 1991.

[21] L. Tong, "Bond strength for adhesive-bonded single-lap joints," Acta Mechanica, vol. 117, no. 1-4, pp. 101-113, 1996.

[22] J. M. Liu and T. Sawa, "Stress analysis and strength evaluation of single-lap band adhesive joints subjected to external bending moments," Journal of Adhesion Science and Technology, vol. 13, no. 6, pp. 729-749, 1999.

[23] E. Sancaktar and S. Kumar, "Selective use of rubber toughening to optimize lap-joint strength," Journal of Adhesion Science and Technology, vol. 14, no. 10, pp. 1265-1296, 2000.

[24] J. M. Liu and T. Sawa, "Stress analysis and strength evaluation of single-lap adhesive joints combined with rivets under external bending moments," Journal of Adhesion Science and Technology, vol. 15, no. 1, pp. 43-61, 2001.

[25] E. Sancaktar and P. Nirantar, "Increasing strength of single lap joints of metal adherends by taper minimization," Journal of Adhesion Science and Technology, vol. 17, no. 5, pp. 655-675, 2003.

[26] R. D. S. G. Campilho, M. D. Banea, A. M. G. Pinto, L. F. M. da Silva, and A. M. P. de Jesus, "Strength prediction of singleand double-lap joints by standard and extended finite element modelling," International Journal of Adhesion and Adhesives, vol. 31, no. 5, pp. 363-372, 2011.

[27] A. M. G. Pinto, R. D. S. G. Campilho, I. R. Mendes, S. M. Aires, and A. P. M. Baptista, "Effect of hole drilling at the overlap on the strength of single-lap joints," International Journal of Adhesion and Adhesives, vol. 31, no. 5, pp. 380-387, 2011.

[28] P. N. B. Reis, J. A. M. Ferreira, and F. Antunes, "Effect of adherend's rigidity on the shear strength of single lap adhesive joints," International Journal of Adhesion and Adhesives, vol. 31, no. 4, pp. 193-201, 2011.
[29] P. Hu, X. Han, W. D. Li, L. Li, and Q. Shao, "Research on the static strength performance of adhesive single lap joints subjected to extreme temperature environment for automotive industry," International Journal of Adhesion and Adhesives, vol. 41, pp. 119-126, 2013.

[30] W. Xu and Y. G. Wei, "Assessments for impact of adhesive properties: modeling strength of metallic single lap joints," Journal of Adhesion Science and Technology, vol. 27, no. 1, pp. 9-29, 2013.

[31] B. Zhao, Z. H. Lu, and Y. N. Lu, "Two-dimensional analytical solution of elastic stresses for balanced single-lap jointsvariational method," International Journal of Adhesion and Adhesives, vol. 49, pp. 115-126, 2014.

[32] S. K. Parida and A. K. Pradhan, "Effect of material anisotropy on delamination damage in adhesive bonded lap shear joints made with curved laminated FRP composite panels," Iranian Journal of Science and Technology, Transactions of Mechanical Engineering, vol. 40, no. 4, pp. 275-287, 2016.

[33] V. Valeva and J. Ivanova, "Influence of the interface gap on the stress behaviour of single lap joints," Comptes Rendus de l'Acad'emie Bulgare des Sciences, vol. 69, no. 9, pp. 1203-1212, 2016.

[34] H. Adin, "Effect of overlap length and scarf angle on the mechanical properties of different adhesive joints subjected to tensile loads," Materials Testing, vol. 59, no. 6, pp. 536-546, 2017. 


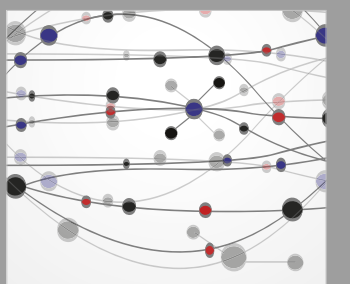

The Scientific World Journal
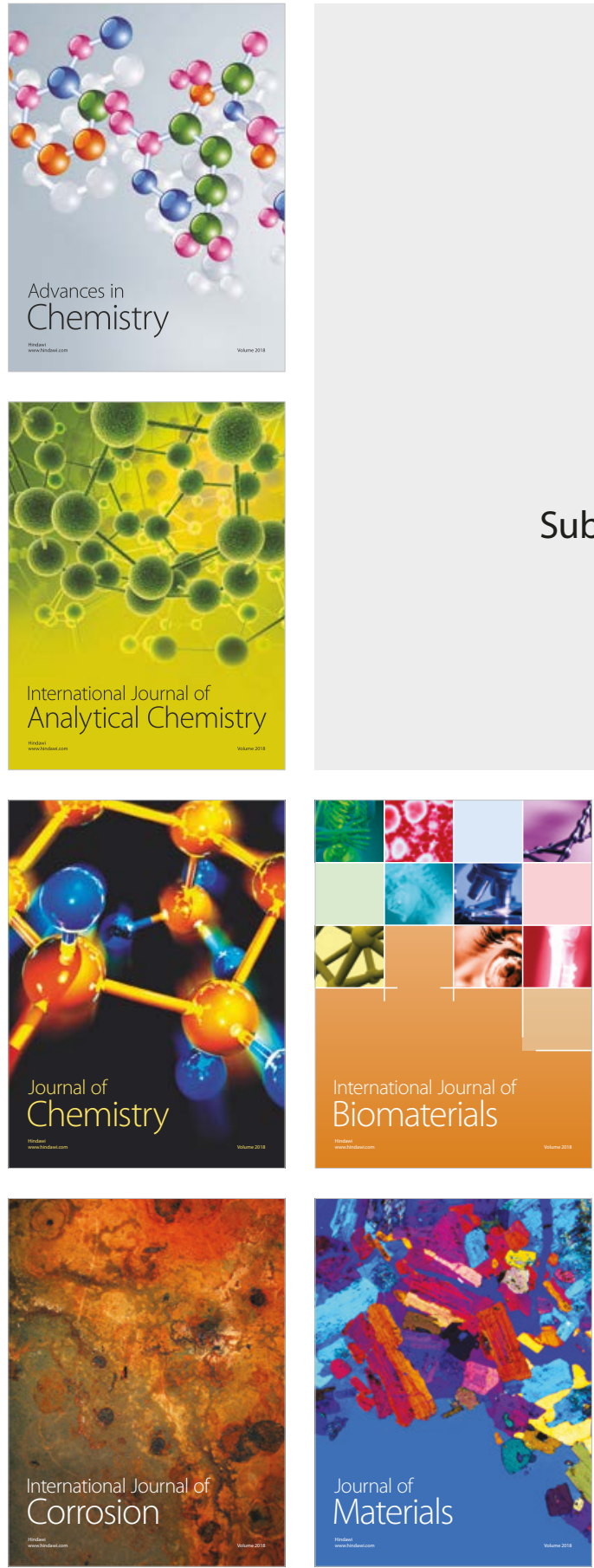

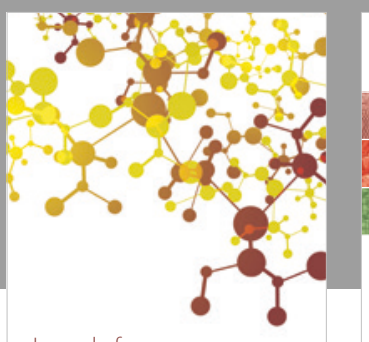

Journal of

Applied Chemistry
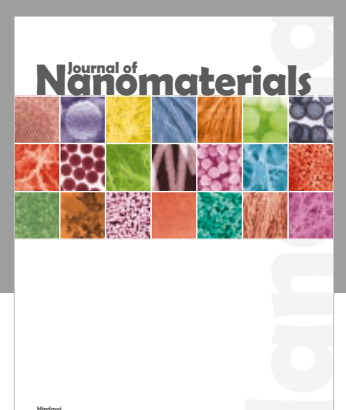

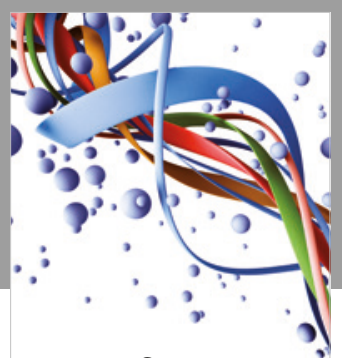

Scientifica

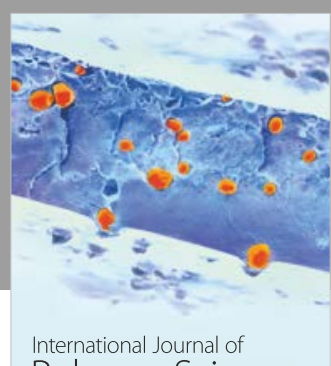

Polymer Science

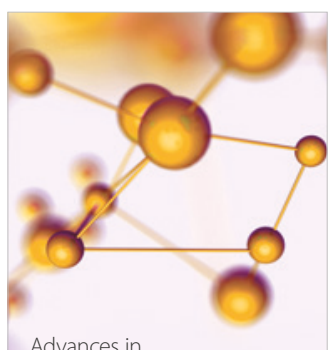

Physical Chemistry
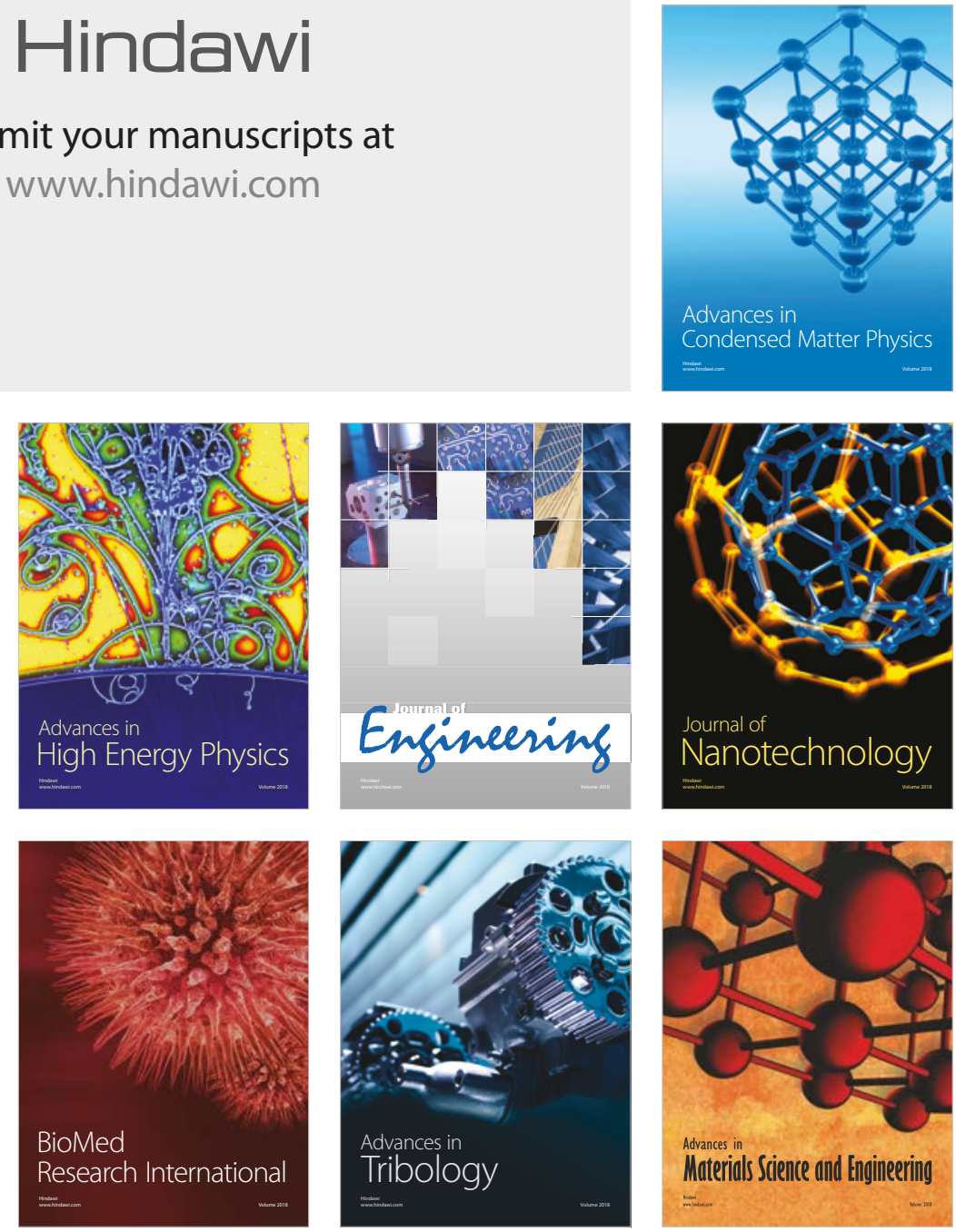